\title{
An experimental and numerical study on nonlinear impact responses of steel-plated structures in an Arctic environment
}

\author{
Ki Jong Kimª, Jong Hwan Lee ${ }^{\mathrm{a}}$, Dae Kyeom Parkª Bo Gyeong Jung ${ }^{\mathrm{a}}$, Xu Hanª Bong Ju Kimª \\ Toshiyuki Matsumoto ${ }^{\mathrm{b}}$, Su Hwan Byeon ${ }^{\mathrm{c}}$ and Jeom Kee Paik ${ }^{\mathrm{a}, \mathrm{d}^{*}}$ \\ a The Korea Ship and Offshore Research Institute (The Lloyd's Register Foundation Research \\ Centre of Excellence), Pusan National University, Busan, Korea \\ ${ }^{\mathrm{b}}$ ClassNK, Tokyo, Japan \\ ${ }^{c}$ STX Offshore and Shipbuilding Co., Ltd, Jinhae, Korea \\ ${ }^{\mathrm{d}}$ Department of Mechanical Engineering, University College London, UK
}

\begin{abstract}
Ships and offshore platforms that operate in Arctic regions at low temperatures are likely subjected to impact loads that arise from collisions with icebergs. The aim of this paper was to examine the nonlinear impact response of steel-plated structures in an Arctic environment. In addition to material tensile tests for characterisation of the mechanical properties of polar-class high-tensile steel of grade DH36, an experimental study was undertaken in a dropped-object test facility on steel-plated structure models under impact loads and at low temperatures equivalent to those in Arctic regions. LS-DYNA nonlinear finite element computations were also performed for the corresponding test models. We conclude that nonlinear finite element analyses are useful in the analysis of the nonlinear impact structural responses involving yielding, crushing and brittle fractures at low temperatures as long as the modelling techniques are adequate. The conclusions and insights developed in this paper should be useful in the safety design of ships and offshore platforms intended for operation in Arctic regions.
\end{abstract}

Keywords: Nonlinear impact response, Arctic environment, collisions with iceberg, low

\footnotetext{
*Corresponding Author: Telephone: +82 51510 2429; fax: +82 5128836.

E-mail address: jeompaik@ pusan.ac.kr (J.K. Paik)
} 
temperature, steel-plated structure, accidental limit state design, safety design

\section{Introduction}

An era of North Pole routes, which have been said to be 'dream waterways', is becoming a reality due to the effects of global warming. With the opening of the North Pole passages, the market for shipbuilding and offshore industries is expected to become more active with economical transportation of cargo and the development of natural resources in association with the Arctic Ocean.

When the Arctic passages actually open, ships that use those waterways and the related offshore structures may be exposed to risks associated with accidents such as collisions with icebergs. Safety studies regarding such accidents are thus required to meet health, safety and environmental requirements. As far as collisions are concerned, structural safety is evaluated on the basis of the collision energy absorption capability of the structure until the accidental limit state is reached. Because the energy absorption capability can be obtained by integrating the area below the reaction forces versus the indentation curve of the structure, structural crashworthiness involving crushing, yielding and fracture forces must be characterised by obtaining the resulting force-indentation curve of the structure in the event of a collision or grounding accident [1-6].

In this connection, a wide range of review has conducted in terms of collision [7-17] and most of these studies mainly focused on the performance of damaged ships after collision and grounding events. Youssef et al. [18] proposed a method for accessing the risk of ship hull collapse following a collision. A set of credible collision scenarios which represent the entire range of possible collision accidents is selected using a sampling technique based on probability density distributions of influencing parameters. Kim et al. [19] also investigated the environmental consequences of the involvement of oil tankers in collision using probabilistic 
approaches. Besides, Ehlers et al. [20] examined the numerical and experimental investigation on collision resistance of the X-core structure. The analysis includes a detailed investigation of the non-linear plate and laser weld material behaviour using optical, full-field strain measurements. The resulting material relationships are implemented into the finite element model.

In this process, the effects of the environmental conditions associated with the low temperatures in Arctic regions should, of course, be taken into account. An extensive review of some recent developments in the dynamic inelastic behaviour of structures was made by Jones [21], while a number of useful studies [22-34] associated with nonlinear structural responses due to impact loads have been undertaken in recent years in the literature. Jones [35-37] developed an analytical model to predict the maximum plastic deformation of rectangular plates under simply supported and fully clamped boundary conditions. The model was validated with experimental results at room temperature (RT) obtained for plates that underwent impact from blunt, conical and hemispherical projectiles. Cho and Lee [38] investigated the responses of stiffened steel plates subjected to impact loads (approximately 1.6 to $6.2 \mathrm{~m} / \mathrm{s}$ ) at RT and developed design formulas for the prediction of the extent of the resulting damage to the stiffened plates. Liu et al. [39] studied the impact response and failure mode of thin aluminium plates under impact loads $(4.5 \mathrm{~m} / \mathrm{s})$ and validated the experimental results with numerical studies at RT. Mohotti et al. [40] examined the impact resistance of aluminium plates subjected to low-velocity impact ( 5 to $15 \mathrm{~m} / \mathrm{s}$ ) and developed an analytical model to predict the out-ofplane deflection of the aluminium plates. Paik and Won [41] developed a new empirical formula as a function of the impact velocity, the properties of the target plate and the striker for the impact perforation energy on steel-plated structures. Haris and Amdahl [42] proposed a new analytical formula that can be used to calculate the axial force of steel-plated structures under impact loads. Most recently, Samuelides [43] discusses the methods that have been developed 
and used for the determination of the damage of ship structures subjected to impact loads. It was mainly focused in association with realistic modelling of the material behaviour. To the best of our knowledge, however, the above-mentioned studies were all performed at RT rather than at a low temperature.

When designing steel-plated structures for low-temperature applications, it is important that the influence of low-temperature on the material properties, especially from the point of view of yield and tensile strength should be considered. In general, an increase in yield and tensile strength at low temperature is characteristic of the materials. However, the performance of structures in low-temperatures can adversely affect the tensile toughness towards reduced way. Tensile toughness is a measure of a material's brittleness or ductility; it is often estimated by calculating the area beneath the stress-strain curve. Experimental studies conducted in lowtemperature conditions but in a quasi-static loading condition can be found in the literature. Paik et al. [44] investigated the effects of low temperature $\left(-40^{\circ} \mathrm{C}\right.$ and $\left.-60{ }^{\circ} \mathrm{C}\right)$ on the crushing response of steel-plated structures. Dipaolo and Tom [45] examined the same topic [44] at -45 ${ }^{\circ} \mathrm{C}$. McGregor et al. [46] studied the crushing characteristics of aluminium-plated structures and found that the average crushing force of hexagonal aluminium box sections increased as the temperature decreased (from RT to $-40{ }^{\circ} \mathrm{C}$ ). With respect to impact loads at low temperatures, Min et al. [47] conducted an experiment associated with the plastic deformation of steel-plated structures subjected to impact loads (approximately 5 to $5.5 \mathrm{~m} / \mathrm{s}$ ) and performed comparative studies through numerical analysis. The experiment was conducted at $-30{ }^{\circ} \mathrm{C}$ and $-50{ }^{\circ} \mathrm{C}$ using DH36. Manjunathan and Surendran [48] studied dynamic fracture toughness of aluminium 6063 with multilayer composite patching at lower temperatures.

At present, studies on the nonlinear impact responses of steel or aluminium structures at low temperatures are lacking, and more research regarding Arctic environments is necessary. The objective of this study was therefore to provide useful contributions and insights associated 
with the nonlinear impact responses of steel-plated structures at low temperatures.

\section{Material tensile test}

\subsection{Test set-up for the quasi-static test}

Quasi-static $(0.05 \mathrm{~mm} / \mathrm{s})$ tensile tests were conducted at $\mathrm{RT}$ and at $-60{ }^{\circ} \mathrm{C}$ to determine the mechanical properties of DH36, which indicates polar-class high-tensile steel. The droppedobject experiment described later was performed on steel-plated structures made of DH36. The specimen size and shape are shown in Fig. 1(a) in accordance with the requirements of the American Society for Testing and Materials E8 [49]. The specimens were extracted on the basis of the rolling direction from the parent plate-sheet. The gauge length of the specimen was 50 $\mathrm{mm}$ and its thickness was $6 \mathrm{~mm}$. Table 1 shows the major chemical composition of DH36.

The tensile test was conducted with a $1,000 \mathrm{kN}$ universal testing machine at the Korea Ship and Offshore Research Institute of Pusan National University, Korea. A liquid-nitrogen-cooled chamber was used to create the low-temperature environment. Fig. 1(b) shows the appearance of the equipment set-up for the tensile coupon test. Sensors for the measurement of applied forces and displacements at every 0.1 second interval were used with a load cell and extensometer. The temperature was measured at 1 second intervals and kept constant during the test within $3{ }^{\circ} \mathrm{C}$ of the target temperature.

Fig. 1. Quasi-static test set-up: (a) test specimen and (b) universal testing machine with an environment chamber. Table 1 Chemical composition of DH36 parent plate (\%).

\subsection{Test set-up for the dynamic test}

A dynamic tensile coupon test $(5 \mathrm{~mm} / \mathrm{s}$ and $100 \mathrm{~mm} / \mathrm{s})$ was also undertaken with the same material and temperatures. In contrast to the quasi-static test, dynamic tensile tests have no firmly established national or international standards [50]. For the dynamic test, the parallel section of the specimen should be designed for uniform elongation during dynamic straining 
[51]. It has been pointed out that a short parallel section of the specimen can cause non-uniform elongation and that asymmetric fractures biased to the loading side always occur for long parallel sections. An excessively long parallel section can also involve quite different stress waves.

Taking these observations into account, a specimen size and shape with a gauge length of 50 $\mathrm{mm}$ and a thickness of $6 \mathrm{~mm}$ was designed as shown in Fig. 2(a). The test was conducted with an MTS servo-hydraulic testing machine $(500 \mathrm{kN})$ at the Korea Ship and Offshore Research Institute of Pusan National University, Korea. Liquid nitrogen was injected into the chamber to attain the low target temperature, as shown in Fig. 2(b). A digital image correlation (DIC) technique using a high-speed camera was used as shown in Fig. 2(c) to satisfy the condition of uniform axial displacement along the axis of the specimen. The sampling rate of the high-speed camera was $1,000 \mathrm{~Hz}$ for $5 \mathrm{~mm} / \mathrm{s}$ and $20 \mathrm{kHz}$ for $100 \mathrm{~mm} / \mathrm{s}$.

Fig. 2. Dynamic test set-up: (a) test specimen, (b) MTS servo-hydraulic testing machine with an environment chamber and (c) displacement measurement by DIC.

\subsection{Test results and discussion}

Fig. 3 shows the engineering stress-strain curves of $\mathrm{DH} 36$ at $\mathrm{RT}$ and at $-60{ }^{\circ} \mathrm{C}$ under quasistatic and dynamic conditions. The mechanical properties of DH36 are summarised in Table 2.

Fig. 3. Engineering stress-strain curves with different velocities: (a) RT and (b) $-60{ }^{\circ} \mathrm{C}$.

Table 2 Mechanical properties of DH36.

At RT, the test results showed that the yield strength $\left(\sigma_{Y}\right)$ and tensile strength $\left(\sigma_{T}\right)$ increased as the loading speed increases. The yield strength increased by $5.5 \%(5 \mathrm{~mm} / \mathrm{s})$ and $13.2 \%(100$ $\mathrm{mm} / \mathrm{s})$, and the tensile strength increased by $3.7 \%(5 \mathrm{~mm} / \mathrm{s})$ and $8.5 \%(100 \mathrm{~mm} / \mathrm{s})$ compared with the quasi-static test results. However, the fracture strain decreased by $8.5 \%(5 \mathrm{~mm} / \mathrm{s})$ and $11 \%(100 \mathrm{~mm} / \mathrm{s})$ with an increase in the loading speed. At $-60{ }^{\circ} \mathrm{C}$, the yield strength increased by $8.5 \%(5 \mathrm{~mm} / \mathrm{s})$ and $17.7 \%(100 \mathrm{~mm} / \mathrm{s})$, and the tensile strength decreased by $1.3 \%(5 \mathrm{~mm} / \mathrm{s})$ 
and increased by $2.8 \%(100 \mathrm{~mm} / \mathrm{s})$ compared with the quasi-static results. The fracture strain decreased by $19.2 \%(5 \mathrm{~mm} / \mathrm{s})$ and $22.1 \%(100 \mathrm{~mm} / \mathrm{s})$ with an increase in the loading speed. Fig. 4 presents the mechanical properties of DH36 as a function of the strain rate based on the test results.

Through the material tensile test, the changing of material properties of the DH36 in terms of yield and tensile strength increased due to strain rate and low-temperature. However, it was confirmed that the fracture strain decreased as expected. Also, it was found that the yield strength and fracture strain of the material were more affected by the strain rate at low temperatures. However, the tensile strength was not largely dependent on the strain rate.

Fig. 4. Mechanical properties of DH36 as a function of strain rate: (a) yield strength, (b) tensile strength and (c) fracture strain.

\section{Dropped-object tests}

\subsection{Test models and scenarios}

Fig. 5. Structural specimens for the dropped-object test.

Two types of test models were used for the dropped-object tests in small-scale, as shown in Fig. 5. The type I model was an unstiffened plate. The type II model was a stiffened panel with cross-shaped flat bar stiffeners welded onto it. The edges of the test models were also welded to the surrounding rigid jig, which was fully clamped by bolts. Both types of plates were 1,200 $\mathrm{mm} \times 1,200 \mathrm{~mm} \times 6 \mathrm{~mm}$. The drop height of the striker was $3 \mathrm{~m}$ at RT and $5 \mathrm{~m}$ at $-60{ }^{\circ} \mathrm{C}$ for type I and type II models, separately. Considering the test facility such as load-cell capacity, low-temperature chamber and test model, two sets of tests of different drop height for the models were undertaken. Table 3 shows the scenarios for dropped-object testing.

Table 3 Scenarios for the dropped-object testing. 


\subsection{Experimental set-up and procedure}

The dropped-object test was carried out using a cone-shaped striker. The weight that the striker applied to the test models, including that of the striker holder, was about $11.5 \mathrm{kN}$. The striker was set to hit the centre of the test model. Fig. 6(a) shows the dropped-object test facility with the high-speed camera installed. A DIC technique was used to measure the penetration of the striker during the experiment. The sampling rate of the high-speed camera was $10 \mathrm{kHz}$.

Fig. 6. Experimental set-up: (a) dropped-object test facility and test models with installed high-speed camera, (b) low-temperature chamber, (c) temperature history and (d) strain gauge location.

To simulate an Arctic environment, a low-temperature chamber was made with an insulating system. Fig. 6(b) shows the installed low-temperature chamber into which liquid nitrogen was injected to reach a low target temperature equivalent to that in an Arctic environment. A T-type thermocouple was used for the practical measurement of the temperature of the test models. The part of the thermocouple that was exposed to the environmental temperature was wrapped with insulating materials so as not to be affected by the temperature in the chamber and was kept close to the test model.

The test model was divided into four zones. The temperature was recorded at the centre of each zone. Fig. 6(c) indicates the temperature history of the test model during the test. The experiment began after the temperature was lowered to about $5^{\circ} \mathrm{C}$ because a loss of temperature could occur when the chamber was removed shortly before testing with a dropped-object.

Furthermore, four strain gauges were attached at right angles to confirm the axis symmetry of the strain at sites $150 \mathrm{~mm}$ and $500 \mathrm{~mm}$ from the centre of the test model as shown in Fig. $6(d)$.

\subsection{Experimental results at $\mathrm{RT}$}

Fig. 7. Test models after test at RT: (a) type I and (b) type II.

Figs. 7(a-b) show the lack of significant deformation or failure of the test model after the 
experiment. The high-speed camera measured the velocity of the striker at about $7.06 \mathrm{~m} / \mathrm{s}$ just before impact loading. The maximum indentation values of the type I and type II models were $109.28 \mathrm{~mm}$ and $74.87 \mathrm{~mm}$, respectively, as shown in Fig. 8(a), where 'Reaction=0' on the graph indicates that the force signal equals zero. The maximum forces of the two models were $497.97 \mathrm{kN}$ and $497.07 \mathrm{kN}$, respectively, as shown in Fig. 8(b). Fig. 8(c) shows the force versus indentation curves, in which the gradient of the type II plates rather than the type I plates rapidly increased when the impact load was applied for the first time because the two structures differed in their overall stiffness. When the load was removed, both types showed a spring-back phenomenon; the type I and type II plates rebounded $23.71 \mathrm{~mm}$ and $14.72 \mathrm{~mm}$, respectively. These results showed that the type II plates with stiffeners had greater initial stiffness.

Fig. 8(d) shows the energy absorption versus indentation curves for the type I and type II models obtained by the experiment. It is obvious that the type II stiffened panel model is superior to the type I unstiffened plate in terms of energy absorption capability according to the indentation.

The locations of the strain gauges at $150 \mathrm{~mm}$ on both test models were confirmed to be symmetric, as shown in Figs. 8(e-f). The strains of the type I model measured at $500 \mathrm{~mm}$ were confirmed to be symmetric in the right-angle direction, as shown in Fig. 8(g), but those of the type II model were asymmetric, as shown in Fig. 8(h).

Fig. 8. Test results at RT: (a) indentation-time curves, (b) force-time curves, (c) force-indentation curves, (d) absorbed energy-indentation curves, (e) strain-time curves for type I model at $150 \mathrm{~mm}$, (f) strain-time curves for type II model at $150 \mathrm{~mm}$, (g) strain-time curves for type I model at $500 \mathrm{~mm}$ and (h) strain-time curves for type II model at $500 \mathrm{~mm}$.

\subsection{Experimental results at $-60^{\circ} \mathrm{C}$}

Fig. 9. Test models after test at $-60^{\circ} \mathrm{C}$ : (a) type I and (b) type II.

After the experiment, the type I plate had no fractures, but the type II plate had suffered brittle fracture. Figs. 9(a-b) compare the deformed shapes of the two test models after the 
experiment. Both models have an initial velocity of $8.57 \mathrm{~m} / \mathrm{s}$ at the moment of impact. The maximum indentation of the type I model was $104.07 \mathrm{~mm}$ (Fig. 10(a)) and the maximum forces were $660.25 \mathrm{kN}$ (Fig. 10(b)). Data on the maximum indentation and forces could not be obtained for the type II model because the striker penetrated through the structure. In terms of force versus indentation curves (Fig. 10(c)), the gradient of the type II model rapidly increased shortly after impact loading as compared with the type I model, similar to the results of the experiment at RT. This result implies that the stiffened panels can sustain deformations more effectively than unstiffened plates, even at low temperatures. The effects of spring-back were also observed for the type I model; a value of $20.13 \mathrm{~mm}$ was demonstrated. In the type II model, no spring-back phenomenon was confirmed because the fracture was followed by the penetration of the striker through the test model.

Fig. 10(d) compares the energy absorption capabilities for the type I and type II models, as obtained by the experiment at $-60{ }^{\circ} \mathrm{C}$. It is obvious that the type II stiffened panel model is superior to the type I unstiffened plate model in terms of energy absorption capability according to the indentation until fracture occurs, but the brittle fracture occurred in the type II model resulted in sudden loss of the energy absorption capability.

Upon comparison of the strain values, no data regarding the strain at $150 \mathrm{~mm}$ for either model could be measured until the test ended because the strain gauges were broken as a result of the shocks and structural fractures, as shown in Figs. 10(e-f). At the $500 \mathrm{~mm}$ position, the sections of A-A' and B-B' were confirmed to be symmetric for the type I model, as shown in Fig. 10(g), and the strain gauge attached on the A-A' section confirmed permanent plastic deformation of about 0.00093, as shown in Fig. 10(h).

Fig. 10. Test results at $-60{ }^{\circ} \mathrm{C}$ : (a) indentation-time curves, (b) force-time curves, (c) force-indentation curves, (d) absorbed energy-indentation curves, (e) strain-time curves for type I model at $150 \mathrm{~mm}$, (f) strain-time curves for type II model at $150 \mathrm{~mm}$, (g) strain-time curves for type I model at $500 \mathrm{~mm}$ and (h) strain-time curves for type II model at $500 \mathrm{~mm}$. 


\section{Nonlinear finite element analysis}

The nonlinear impact responses obtained in the dropped-object tests were compared by nonlinear finite element (FE) analysis. In this study, LS-DYNA 3D, a general-purpose FE analysis code that is appropriate for nonlinear explicit dynamic simulations, was used for the analysis of the structural responses of the test models.

\subsection{FE modelling}

The test models, striker and jig were imitated as much as possible to conduct FE modelling like that shown in Fig. 11. The test structures were modelled by four-node quadratic elements with five-integration points throughout the thickness defining the Belytschko-Lin-Tsay shell element formulation. These shell elements were based on a combined co-rotational and velocity-strain formulation [52]. The piecewise linear plasticity material model (MAT 24) was adopted to allow failing elements to be removed at the critical strain [53]. The welded area was also considered by increasing the element thickness by $50 \%$ as indicated in Fig. 12. This modelling technique was relevant because welding may increase the resistance of the stiffener and help the transverse transition between the stiffener and the plate [54-55].

Because the size of the meshes greatly affects the computational time and accuracy of the result, a mesh-convergence test was performed for the type I and type II models before the actual FE analysis. As a result, the best-size mesh for the shell elements was determined to be $20 \mathrm{~mm} \times 20 \mathrm{~mm}$.

Fig. 11. Finite element model applied.

Fig. 12. Weld elements at the plate-stiffener intersections.

The boundary conditions of the test jig for the FE model were fixed in the vertical direction and the bolting spots were fixed in the horizontal direction. The cone-shaped striker was set to be the rigid body block. The initial velocities of $7.06 \mathrm{~m} / \mathrm{s}$ at $\mathrm{RT}$ and $8.57 \mathrm{~m} / \mathrm{s}$ at $-60{ }^{\circ} \mathrm{C}$, as 
measured by the high-speed camera, were used as input data. The contact between the striker and the structure was set to be the 'automatic node to surface'. In the type II model, an 'automatic single surface' was added to reflect the folded mechanism of the structure. The static and kinetic coefficients of friction were assumed to be 0.3 for all analyses.

\subsection{Material modelling}

\subsubsection{True stress-strain curve}

The effects of low temperature can differ in terms of strain hardening. Table 4 shows the strain hardening exponents $(n)$ and strength coefficients $(K)$ determined by the material tensile tests for DH36. It was found that the properties of hardening and strength were better at low temperatures than at RT.

Table 4 Strain hardening exponents and strength coefficients for DH36.

Fig. 13 shows the true stress-true plastic strain curves that were transformed through Eqs. (1) and (2) at $\mathrm{RT}$ and $-60^{\circ} \mathrm{C}$ in the quasi-static condition.

(1)

$$
\sigma_{t}=\sigma_{e}\left(1+\varepsilon_{e}\right)
$$

$$
\varepsilon_{t}=\ln \left(1+\varepsilon_{e}\right)
$$

where $\sigma_{e}=$ engineering stress, $\varepsilon_{e}=$ engineering strain, $\sigma_{t}=$ true stress and $\varepsilon_{t}=$ true strain.

Fig. 13. True stress-true plastic strain curves.

As the engineering stress-strain curve does not give a true indication of the deformation characteristics of a material, it was necessary to use the true stress-strain curve that represents the basic plastic-flow characteristics of the materials [56]. In the true curve until the onset of necking, the true stress $\left(\sigma_{t}\right)$ and the true plastic strain $\left(\varepsilon_{t}\right)$ were expressed in terms of the 
engineering stress $\left(\sigma_{e}\right)$ and the engineering strain $\left(\varepsilon_{e}\right)$. In this way, the low-temperature hardening effects could be considered using the piecewise flow stress at $-60{ }^{\circ} \mathrm{C}$.

\subsubsection{Effects of strain rate}

The material properties such as yield stress should be considered by taking into account the dynamic effects, which are called strain rate effects. The Cowper-Symonds model is usually used to evaluate the strain rate effects $[1,57]$. The strain rate effects were taken into consideration by using the dynamic plastic-hardening constitutive equation (Eq. (3)) of Cowper-Symonds that is most widely used in the naval architecture and offshore engineering fields [2-5]. The Cowper-Symons [57] have been proposed the coefficients for mild steel, $C=40.4, q=5$ and Paik and Chung [58] have been suggested the coefficient for high-tensile steel, $C=3200, q=5$, respectively. Fig. 14 plots the Cowper-Symonds equation together with the relevant coefficients for mild or high-tensile steel. It is obvious that the mild steel is sensitive more than high-tensile steel. It is also evident that the material yield strength increases with increase in the strain rate and these coefficients are dependent on the material types, among other factors.

$$
\frac{\sigma_{Y d}}{\sigma_{Y}}=1+\left(\frac{\dot{\varepsilon}}{C}\right)^{\frac{1}{q}}
$$

where $\sigma_{Y}$ and $\sigma_{Y d}$ are the yield stress under static and dynamic loads, respectively, $\dot{\varepsilon}$ is the strain rate, and $C$ and $q$ are the coefficients determined by experiment.

In the present paper, the coefficients, both $C=3200, q=5$ and $C=40.4, q=5$ were compared to investigate the difference of the results when it comes to the high-tensile steel in the FE analysis.

Fig. 14. Dynamic yield strength plotted versus strain rate for mild and high tensile steel. 


\subsubsection{Fracture criterion}

The tensile test can determine another important material property, the fracture strain, which is presented in Table 2. However, it is necessary to mention that failure due to material rupture is not well resolved numerically because the fracture length is smaller than the side length of the elements in the finite element model. Thus, the elements used in finite element models cannot capture such a local phenomenon [59].

The fracture model used in the present paper was the shear fracture criterion. The shear criterion, sometimes referred to as the criterion of equivalent strain, is a phenomenological representation of the initiation of damage due to shear band localization. The criterion presumes that the fracture initiates when the accumulated equivalent plastic strain reaches the material failure strain. It is frequently used in simulations of ship collision and grounding and has gained popularity due to its simple formulation [30], [60-62]. In its simplest form, the only input used is the critical fracture strain that is affected by various factors including mesh size, strain rate and low-temperature. It is also affected by material models of the finite-element simulation in terms of the stress-strain relationships. In association with this, the DNV [63] and NTSI [64] proposed the values of shear fracture criterion for accidental events: 0.2 for mild steel and 0.15 for high-tensile steel. However, they do not cover the combined effects of low temperature and strain rate [65].

Apart from element size, computation time and computation code (Implicit/Explicit), lowtemperature and high strain rate affected the failure phenomenon in the FE analysis. Two parameters should be considered together with others to get a reliable result. A failure strain was applied in LS-DYNA with an inputted number, although the strain rates changed in every computation step. Furthermore, even though the fracture strains were obtained from experiments, the values could not directly be applied in the FE analysis. To consider the fracture strain in FEA, the critical fracture strain was used as a function of the element size, namely [4] 


$$
\frac{\varepsilon_{f c r}}{\varepsilon_{f}}=4.1+\left(\frac{t}{S}\right)^{0.58}
$$

where $\varepsilon_{f}$ is the fracture strain of the material obtained from the tensile test, $\varepsilon_{f c r}$ is the critical fracture strain for FE simulations, $S=$ mesh size (length), and $t=$ plate thickness of the material. In the present paper, the failure strains that showed relevant indentations with experiments were determined and used in the FE analysis. The fracture strains used in FEA are shown in Fig.15.

Fig. 15. Critical fracture strain for FE simulations.

\subsection{Experimental results versus nonlinear FE computations}

\subsubsection{At RT}

Figs. 16(a-b) and Figs. 17(a-b) present the stress distributions obtained by LS-DYNA computations for the type I and II models with different coefficients, respectively, at RT. In addition, Figs. 18(a-h) show the comparison of the results of the experiment and the FE analysis. These results are summarised in Table 5.

Fig. 16. Stress distribution for type I model at RT: (a) $C=3200$ and $q=5$ and (b) $C=40.4$ and $q=5$.

Fig. 17. Stress distribution for type II model at RT: (a) $C=3200$ and $q=5$ and (b) $C=40.4$ and $q=5$.

Table 5 Comparative results at RT.

The type I model applied $C=3200$ and $q=5$ showed good agreement in association with indentation and force. The differences between the experimental results and those of the FE analysis in terms of indentation and force were about $-0.4 \%$ and $-3 \%$, respectively. However, in case of $C=40.4$ and $q=5$, the results showed low values in indentation and was overestimated in forces as shown in Figs. 18 (a), (c). In the type II model inputted $C=3200$ and $q=5$, the differences of the forces became slightly greater, but those of the FE analyses were still at most 
$-5.3 \%$ and $9.8 \%$ against the test. In comparison to the relation between force and indentation as shown in Fig. 18(f), a similar tendency was confirmed, except for the early stages of the forces. Figs. 18(g-h) compare the absorbed energy versus indentation curves between the experiment and FEA for the type I and type II models, respectively. It can be concluded that using the $C=3200$ and $q=5$ for the high-tensile steel in FEA gives good prediction to the experimental results.

Fig. 18. Comparison of results at RT: (a) indentation-time curves for type I model, (b) indentation-time curves for type II model, (c) force-time curves for type I model, (d) force-time curves for type II model, (e) force-indentation curves for type I model, (f) force-indentation curves for type II model, (g) absorbed energy-indentation curves for type I model and (h) absorbed energy-indentation curves for type II model.

\subsubsection{At $-60{ }^{\circ} \mathrm{C}$}

Figs. 19(a-b) and Figs. 20(a-b) illustrate the results of the FE analysis for types I and II at $60{ }^{\circ} \mathrm{C}$. Figs. $21(\mathrm{a}-\mathrm{h})$ present a comparison of the results. Table 6 displays a summary of the comparison.

Fig. 19. Stress distribution for type I model at $-60^{\circ} \mathrm{C}$ : (a) $C=3200$ and $q=5$ and (b) $C=40.4$ and $q=5$.

Fig. 20. Stress distribution for type II model at $-60^{\circ} \mathrm{C}$ : (a) $C=3200$ and $q=5$ and (b) $C=40.4$ and $q=5$.

Table 6 Comparative results at $-60^{\circ} \mathrm{C}$.

For the type I model used $C=3200$ and $q=5$, the errors of the indentation and force against the experiment were about $11.5 \%$ and $-0.5 \%$, which showed good agreement with the forces. However, the results obtained from $C=40.4$ and $q=5$ were higher than those of the other coefficients. It was observed that the use of constants $C=40.4$ and $q=5$ makes the impact peak force higher than it should. This means that the material strengthening is overestimated by the constants, especially at high strain rate. This tendency is quite similar to the results at RT. The type II model with the brittle fracture showed a similar tendency regarding the force at the initial stage, but a structural response at later stage that sudden rupture occurred was somewhat different indicated by the comparison; the peak load point of the experimental results reached 
about $700 \mathrm{kN}$ while the FE results indicated the lowest value in case of applied $C=3200, q=5$.

Figs. 21(g-h) compare the absorbed energy versus indentation curves between the experiment and FEA for the type I and type II models at $-60{ }^{\circ} \mathrm{C}$, respectively.

Fig. 21. Comparison of results at $-60^{\circ} \mathrm{C}$ : (a) indentation-time curves for type I model, (b) indentation-time curves for type II model, (c) force-time curves for type I model, (d) force-time curves for type II model, (e) forceindentation curves for type I model, (f) force-indentation curves for type II model, (g) Absorbed energy-indentation curves for type I model and (h) Absorbed energy-indentation curves for type II model.

Moreover, it is also meaningful to analyse the total energy absorption capability in the view point of the safety design. Table 7 presents the comparison of the total energy absorption between the experiment and FEA for the type I and type II models, respectively. In experimental results, it was found that the type II stiffened model is also superior to the type I unstiffened model at RT and $-60{ }^{\circ} \mathrm{C}$. The total energy absorption capability for type II model at $-60{ }^{\circ} \mathrm{C}$ refers to the preceding occurrence of the brittle fracture.

Table 7 Total energy absorption.

\section{Discussion}

\subsection{Influence of low-temperature}

When the results for the type II model at RT are compared with those at a low temperature, it can be seen that the relation between force and indentation at the initial stage was almost identical. It was also of a similar level of structural stiffness compared to that in RT conditions and showed a good degree of resistance against deformation. It was found that the initial stiffness of the type II model was maintained at $-60{ }^{\circ} \mathrm{C}$. Also, the presence of stiffeners increased the stiffness of the structure and increased the energy absorption capabilities according to the indentation at both temperatures. However, even though the structure of the type II model can resist deformation at the initial stage at $-60{ }^{\circ} \mathrm{C}$, it fractured after that stage. This is an interesting phenomenon. This finding indicates that although the initial stiffness or 


\section{For publication in International Journal of Impact Engineering}

energy absorption capability of stiffened structure may be higher, the ultimate resistance at the initiation of fracture can be lower at low temperatures. In fact, this is in conflict with the linearelastic method of structure design. Stiffened structures are generally desired to keep deformations small [66]; however, if the stiffened structure is intended to resist impact loads at low temperatures, a new design, which has higher ductility and capable of absorbing high energy, should be developed. However, considering the small-scale test, it should be considered the boundary condition by Heat Affected Zone (HAZ) of the test models that is actually welded. Liu et al. [59] has been pointed out that if the specimen and impact load used in the experiment were too small, the dynamic response of these small specimens will be affected by the boundary conditions.

\subsection{Brittle fracture}

Fig. 22. Brittle fracture for type II model at $-60^{\circ} \mathrm{C}$.

The other point to discuss regards the occurrence of brittle fracture. In the impact engineering, it may be difficult to obtain detailed information on a fracture problem such as that on the stiffened structures in low-temperature because the mechanism and its responses of structures are highly nonlinear. Some penetration problems with failure and its mechanism for the steel plates are published. Yong [67] found that the perforation process of the stiffened-plates is very sensitive to the nose shape of the projectiles. Also, the impact response and failure mode of the steel plates are highly affected by the geometry of the indenters [39]. Fig. 22 shows the scene captured by high-speed camera at the moment of the brittle fracture for type II model at $-60^{\circ} \mathrm{C}$.

Fig. 23. Bottom of type II model at $-60^{\circ} \mathrm{C}$ : (a) crack propagation and (b) local buckling.

It was observed that the crack began at the centre of the test model and then propagated into the welding line in a diagonal direction at $-60{ }^{\circ} \mathrm{C}$, as shown in Fig. 23 (a). In general, materials exposed to low temperatures or impact loads are more likely to suffer brittle fracture. It has 
already been noted that the fracture toughness decreases as thickness increases [68]. As ships and offshore platforms are built with plates much thicker than the $6 \mathrm{~mm}$ plates used in this test, it is fair to envision that brittle fracture would be more likely to occur in Arctic regions. Furthermore, the lateral-torsional buckling of the stiffener (also called tripping) was observed in the type II model at both temperatures, as shown in Fig. 23(b). The lateral-torsional buckling of the stiffeners is a phenomenon in which the failure of a stiffened panel occurs after the stiffener twists sideways about the edge of the stiffener web attached to the plating. When the torsional rigidity of the stiffener is insufficiently strong, the stiffener can twist sideways [2].

\section{Conclusions}

In this study, the nonlinear impact response of steel-plated structures in an arctic environment and its application in simulation are presented. In order to investigate the impact responses of the structures, the experimental approach, i.e. material tensile test and small- scale droppedobject model test was undertaken, and also FE analysis was performed to enhance the interpretation of the tests.

-From the material tensile test, the engineering stress-strain curves were obtained with different velocities, and the changing of the mechanical properties of the material was analysed as a function of strain rate and temperature. All the experimental results were used for the FE analysis as an input data.

-Through the dropped-object model test at RT and $-60{ }^{\circ} \mathrm{C}$, impact response of the steel-plated structures was actually confirmed in the view point of the force, indentation and energy absorption capability. The unstiffened plate model (type I) did not fracture at $-60{ }^{\circ} \mathrm{C}$, and as a result a spring-back phenomenon was observed while the stiffened plate model (type II) showed brittle fracture at the same temperature. In case of small-scale test, it is considered that the boundary conditions and heat affect zone due to welding could influence the test results. Therefore, further experimental studies on full scale or at least large scale test models should 
be undertaken to examine the practical impact responses of steel-plated structures at low temperatures.

-Nonlinear FE analyses using LS-DYNA were also undertaken by comparison with the test results. The material definition for dynamic impact analyses has been considered by means of the true stress-strain curve, the strain rate sensitivity of materials, and the failure strain. The structural responses were considered with both impact loads and low temperatures. In the process of the $\mathrm{FE}$ analysis, the different coefficients, $C=40.4, q=5$ and $C=3200, q=5$ that is widely used in FE analysis, were applied to the test model to confirm the influence of the coefficients. From the comparison, it is recommended that the use of the $C=3200, q=5$ rather than the $C=40.4, q=5$ in FEA is advisable for the high-tensile steel in the impact application. For the reliable result in simulation, however, more refined and realistic approaches for the analysis combined impact loads with low temperatures should be studied.

The North Pole passage is not yet active. However, if these routes open in the near future, the effects of low temperatures on the safety performance and structural integrity of ships and offshore structures that are subjected to impact loads will be very important.

\section{Acknowledgments}

This research was supported by the Leading Foreign Research Institute Recruitment Program through the National Research Foundation of Korea (NRF) funded by the Ministry of Science, Ict \& future Planning (MSIP) (Grant no.: 2014040731). This work was part of the JDP titled 'Limit states design of type B independent LNG cargo tanks', which was funded by Class NK and STX Offshore \& Shipbuilding Co., Ltd. The study was undertaken at the Lloyd's Register Foundation Research Centre of Excellence at Pusan National University. Lloyd's Register Foundation (LRF), a UK registered charity and sole shareholder of Lloyd's Register Group Ltd, invests in science, engineering and technology for public benefit, worldwide. 


\section{References}

[1] Jones N. Structural impact. Cambridge University Press, Cambridge, UK; 1970.

[2] Paik JK, Thayamballi AK. Ultimate limit state design of steel-plated structures. Wiley, Chichester, UK; 2003.

[3] Paik JK, Thayamballi AK. Ship-shaped offshore installations: Design, building, and operation. Cambridge University Press, Cambridge, UK; 2007.

[4] Paik JK. Practical techniques for finite element modeling to simulate structural crashworthiness in ship collisions and grounding (Part I: Theory). Ships and Offshore Structures 2007;2(1):69-80.

[5] Paik JK. Practical techniques for finite element modeling to simulate structural crashworthiness in ship collisions and grounding (Part II: Verification). Ships and Offshore Structures 2007;2(1):81-85.

[6] Paik JK, Seo JK. A method for progressive structural crashworthiness analysis under collisions and grounding. Thin-Walled Structures 2007;45:15-23.

[7] Obisesan A, Sriramula S, Harrigan J. A framework for reliability assessment of ship hull damage under ship bow impact. Ships and Offshore Structures, 2015

[8] Zeng J, Hu Z, Chen G. A steady-state plate tearing model for ship grounding over a coneshaped rock. Ships and Offshore Structures, 2014

[9] Tavakoli MT, Amdahl J, Leira BJ. Analytical and numerical modelling of oil spill from a side tank with collision damage. Ships and Offshore Structures, 2012;7(1): 73-86

[10] Ringsberg JW. Characteristics of material, ship side structure response and ship survivability in ship collisions. Ships and Offshore Structures, 2010;5(1): 51-66

[11] Zhang S, Pedersen PT, Ocakli H. Collisions damage assessment of ships and jack-up rigs. Ships and Offshore Structures, 2015;10(5): 470-478

[12] Haris S, Amdahl J. Crushing resistance of a cruciform and its application to ship collision 
and grounding. Ships and Offshore Structures, 2012;7(2): 185-195

[13] Kumar K, Surendran S. Design and analysis of composite panel for impact loads in marine environment. Ships and Offshore Structures, 2013;8(5): 597-606

[14] Pill I, Tabri K. Finite element simulations of ship collisions: a coupled approach to external dynamics and inner mechanics. Ships and Offshore Structures, 2011;6(1-2): 59-66

[15] Tabri K. Influence of coupling in the prediction of ship collision damage. Ships and Offshore Structures, 2010;7(1): 47-54

[16] Zheng Y, Aksu S, Vassalos D, Tuzcu C. Study on side structure resistance to ship-ship collisions. Ships and Offshore Structures, 2:3, 273-293

[17] Benson S, Downes J, Dow RS. Ultimate strength characteristics of aluminium plates for high-speed vessels. Ships and Offshore Structures, 2011;6(1-2): 67-68

[18] Youssef SAM, Faisal M, Seo JK, Kim BJ, Ha YC, Kim DK, Paik JK, Cheng F, Kim MS. Assessing the risk of ship hull collapse due to collision. Ships and Offshore Structures, 2014

[19] Kim YS, Youssef S, Ince S, Kim SJ, Seo JK, Kim BJ, Ha YC, Paik JK. Environmental consequences associated with collisions involving double hull oil tanker. Ships and Offshore Structures, 2015;10(5): 479-487

[20] Ehlers S, Tabri K, Romanoff J, Varsta P. Numerical and experimental investigation on the collision resistance of the X-core structure. Ships and Offshore Structures, 2012;7(1): 2129

[21] Jones N. Some recent developments in the dynamic inelastic behaviour of structures. Ships and Offshore Structures 2006;1(1):37-44.

[22] Wen HM, Jones N. Experimental investigation of the scaling laws for metal plates struck by large masses. International Journal of Impact Engineering 1993;13(3):485-505.

[23] Corran RSJ, Shadbolt PJ, Ruiz C. Impact loading of plates-an experimental investigation. 
International Journal of Impact Engineering 1983;1(1):3-22.

[24] Zucchelli A, Minak G, Ghelli D. Low-velocity impact behavior of vitreous-enameled steel plates. International Journal of Impact Engineering 2010;37:673-684.

[25] Langseth M, Larsen PK. Dropped objects' plugging capacity of steel plates. International Journal of Impact Engineering 1990;9(3):289-316.

[26] Langseth M, Larsen PK. Dropped objects' plugging capacity of aluminum alloy plates. International Journal of Impact Engineering 1994;15(3):225-241.

[27] Erice B, Pérez-Martín MJ, Gálvez F. An experimental and numerical study of ductile failure under quasi-static and impact loadings of Inconel 718 nickel-base superalloy. International Journal of Impact Engineering 2014;69:11-24.

[28] Liu B, Villavicencio R, Guedes Soares C. On the failure criterion of aluminum and steel plates subjected to low-velocity impact by a spherical indenter. International Journal of Mechanical Sciences 2014;80:1-15.

[29] BØrvik T, Clausen AH, Hopperstad OS, Langseth M. Perforation of AA5083-H116 aluminium plates with conical-nose steel projectiles-experimental study. International Journal of Impact Engineering 2004;30:367-384.

[30] Choung JM, Cho SR, Kim KS. Impact test simulations of stiffened plates using the micromechanical porous plasticity model. Ocean Engineering 2010;37:749-756.

[31] Ehlers S, Østby S. Increased crashworthiness due to arctic conditions - The influence of sub-zero temperature. Marine Structures 2012;28:86-100.

[32] Villavicencio R, Guedes Soares C. Numerical plastic response and failure of a pre-notched transversely impacted beam. Ships and Offshore Structures, 2012;7(4): 417-429.

[33] Rajendran R, Paik JK, Kim BJ. Design of warship plates against underwater explosions. Ships and Offshore Structures, 2006;1(4): 347-356. 
[34] Villavicencio R, Sutherland L, Guedes Soares C. Numerical simulation of transversely impacted, clamped circular aluminium plates. Ships and Offshore Structures, 2012; 7(1): $31-45$.

[35] Jones N. Impact loading of ductile rectangular plates. Thin-Walled Structures 2012;50:6875.

[36] Jones N, Birch RS, Duan R. Low-velocity perforation of mild steel rectangular plates with projectiles having different shaped impact faces. Journal of Pressure Vessel Technology Trans ASME 2008;130.

[37] Jones N, Paik JK. Impact perforation of steel plates. Ships and Offshore Structures 2013;8(5):579-596.

[38] Cho SR, Lee HS. Experimental and analytical investigations on the response of stiffened plates subjected to lateral collisions. Marine Structures 2009;22:84-95.

[39] Liu B, Villavicencio R, Guedes Soares C. Shear and tensile failure of thin aluminium plates struck by cylindrical and spherical indenters. Ships and Offshore Structures 2013. doi:10.1080/17445302.2013.854029

[40] Mohotti D, Ali M, Ngo T, Lu J, Mendis P, Ruan D. Out-of-plane impact resistance of aluminium plates subjected to low velocity impacts. Materials and Design 2013;50:413426.

[41] Paik JK, Won SH. On deformation and perforation of ship structures under ballistic impacts. Ships and Offshore Structures 2007;2(3):217-226.

[42] Haris S, Amdahl J. An analytical model to assess a ship side during a collision. Ships and Offshore Structures 2012;7(4):431-448.

[43] Samuelides M. Recent advances and future trends in structural crashworthiness of ship structures subjected to impact loads. Ships and Offshore Structures 2015;10(5):488-497.

[44] Paik JK, Kim BJ, Park DK, Jang BS. On quasi-static crushing of thin-walled steel 
structures in cold temperature: Experimental and numerical studies. International Journal of Impact Engineering 2011;38:13-28.

[45] Dipaolo BP, Tom JG. Effects of ambient temperature on a quasi-static axial-crush configuration response of thin-wall, steel box components. Thin-Walled Structures 2009;47:984-997.

[46] McGregor IJ, Meadows DJ, Scott CE, Seeds AD. Impact performance of aluminium structures. In: Jones N, Wierzbicki T, editors. Structural crashworthiness and failure (Chapter 10). Oxfordshire, UK: Alcan International Limited, Banbury Laboratory; 1993, $385-421$.

[47] Min DK, Shin DW, Kim SH, Heo YM, Cho SR. On the plastic deformation of polar-class ship's single frame structures subjected to collision loadings. Journal of the Society of Naval Architects of Korea 2012;49:232-238.

[48] Manjunath GL, Surendran S. Dynamic fracture toughness of aluminium 6063 with multilayer composite patching at lower temperatures. Ships and Offshore Structures, 2013;8(2): 163-175.

[49] ASTM E8. Standard test methods for tension testing of metallic materials. American Society for Testing and Materials, West Conshohocken, PA, USA; 2012.

[50] Choung JM, Nam WS, Lee JY. Dynamic hardening behaviors of various marine structural steels considering dependencies on strain rate and temperature. Marine Structures 2013;32:49-67.

[51] Huh H, Kim SB, Song JH, Lim JH. Dynamic tensile characteristics of TRIP-type steel sheets for an auto-body. International Journal of Mechanical Sciences 2008;(50):918-931.

[52] Hallquist JO. LS-DYNA theory manual. Livermore Software Technology Corporation, Livemore, CA, USA; 2010.

[53] Ehlers SA. Procedure to optimize ship side structures for crashworthiness. Journal of 
Engineering for the Maritime Environment 2010;224:1-12.

[54] Villavicencio R, Guedes Soares C. Numerical modeling of laterally impacted plates reinforced by free and end connected stiffeners. Engineering Structures 2012;44:46-62.

[55] Alsos HS, Amdahl J, Hopperstad OS. On the resistance to penetration of stiffened plates, Part II: Numerical analysis. International Journal of Impact Engineering 2009;36:875-887.

[56] Dieter GE. Mechanical behavior under tensile and compressive loads. ASM Handbook 1986;8:99-110.

[57] Cowper G, Symonds P. Strain hardening and strain rate effects in the loading of cantilever beams. Applied Mathematics Report No: 28. Brown University, Providence, RI, USA; 1957.

[58] Paik JK, Chung JY. A basic study on static and dynamic crushing behavior of a stiffened tube. Transactions, The Korean Society of Automotive Engineers (KSAE) 1999;7(1):219-238.

[59] Liu K, Wang Z, Tang W, Zhang Y, Wang G. Experimental and numerical analysis of laterally impacted stiffened plates considering the effect of strain rate. Ocean Engineering. 2015;99:44-54.

[60] Hogstr" om P, Ringsberg JW, Johnson E. Survivability analysis of a struck ship with damage opening-influence from model and material properties uncertainties. Ships and Offshore Structures, 2011;6(4): 339-354.

[61] Liu B, Villavicencio R, Guedes Soares, C. Experimental and numerical plastic response and failure of laterally impacted rectangular plates. Journal of Offshore Mechanics and Arctic Engineering, 2013a;135(4):1-7.

[62] Liu B, Villavicencio R, Guedes Soares, C. Experimental and numerical plastic response and failure of pre-notched transversely impacted beams. International Journal of Mechanical Science. 2013b;77:314-332. 
[63] Det Norske Veritas (DNV). Design against accidental loads. DNV-RP-C204, Oslo, Norway; 2004.

[64] Norwegian Technology Standard Institution (NTSI). Design of steel structures. NORSOK StandardN-004, Oslo, Norway; 2004.

[65] Park DK, Kim BJ, Seo JK, Ha YC, Matsumoto T, Byeon SH, Paik JK. Safety of FLNG hull structures in collisions with icebergs in an arctic environment. Proceedings of the Maritime Convention on Naval Architects and Marine Engineers 2014:Oct 22-25; Houston, USA.

[66] Alsos HS, Amdahl J. On the resistance to penetration of stiffened plates, Part IExperiments. International Journal of Impact Engineering 2009;36:799-807.

[67] Yong C, Wang Y, Tang P, Hua HX. Impact characteristics of stiffened plates penetrated by sub-ordnance velocity projectiles. Journal of Constructional Steel Research 2008;64:634643.

[68] Dowling NE, Mechanical behavior of materials. Pearson Education, London, UK; 2012. 
Table 1

Chemical composition of DH36 parent plate (\%).

\begin{tabular}{c|c|c|c|c|c|c|c|c|c|c|c}
\hline $\mathrm{C}$ & $\mathrm{Si}$ & $\mathrm{Mn}$ & $\mathrm{P}$ & $\mathrm{S}$ & $\mathrm{Ni}$ & $\mathrm{Cr}$ & $\mathrm{Mo}$ & $\mathrm{Cu}$ & $\mathrm{Al}$ & $\mathrm{V}$ & $\mathrm{Ti}$ \\
\hline 0.131 & 0.425 & 1.175 & 0.015 & 0.006 & 0.02 & 0.04 & 0.017 & 0.013 & 0.023 & 0.006 & 0.01 \\
\hline
\end{tabular}

Table 2

Mechanical properties of DH36.

\begin{tabular}{c|c|c|c|c|c}
\hline Temperatures $\left({ }^{\circ} \mathrm{C}\right)$ & Velocity $(\mathrm{mm} / \mathrm{s})$ & Strain rate $\dot{\varepsilon}(/ \mathrm{s})$ & $\sigma_{Y}(\mathrm{MPa})$ & $\sigma_{T}(\mathrm{MPa})$ & $\mathcal{E}_{f}(-)$ \\
\hline \multirow{3}{*}{$\mathrm{RT}$} & 0.05 & 0.001 & 383.7 & 530.2 & 0.345 \\
\cline { 2 - 6 } & 5 & 0.1 & 404.2 & 550.3 & 0.318 \\
\cline { 2 - 6 } & 100 & 2 & 433.7 & 575.8 & 0.309 \\
\hline \multirow{3}{*}{-60} & 0.05 & 0.001 & 446.2 & 606.5 & 0.365 \\
\cline { 2 - 6 } & 5 & 0.1 & 484.1 & 602.2 & 0.295 \\
\cline { 2 - 6 } & 100 & 2 & 525.0 & 627.3 & 0.284 \\
\hline
\end{tabular}

Table 3

Scenarios for the dropped-object testing.

\begin{tabular}{c|c|c|c|c}
\hline No. & Temperature $\left({ }^{\circ} \mathrm{C}\right)$ & Drop height $(\mathrm{m})$ & Model & Stiffener type \\
\cline { 1 - 3 } 1 & \multirow{2}{*}{ RT } & \multirow{2}{*}{3} & Type I & - (none) \\
\cline { 1 - 3 } 2 & \multirow{2}{*}{-60} & \multirow{2}{*}{5} & Type II & Flat bar (cross shaped) \\
\cline { 1 - 3 } 3 & & & Type I & - (none) \\
\cline { 1 - 3 } & & & Type II & Flat bar (cross shaped) \\
\hline
\end{tabular}

Table 4

Strain hardening exponents and strength coefficients for DH36.

\begin{tabular}{c|c|c}
\hline Temperature $\left({ }^{\circ} \mathrm{C}\right)$ & $n$ & $K(\mathrm{MPa})$ \\
\hline $\mathrm{RT}$ & 0.214 & 936.2 \\
\hline-60 & 0.232 & 1103.8 \\
\hline
\end{tabular}


Table 5

Comparative results at RT.

\begin{tabular}{c|c|c|c|c|c|c}
\hline & Model & Experiment & $\begin{array}{c}\text { FEA } \\
(C=3200, q=5)\end{array}$ & Error $(\%)$ & $\begin{array}{c}\text { FEA } \\
(C=40.4, q=5)\end{array}$ & Error $(\%)$ \\
\hline \multirow{2}{*}{$\begin{array}{c}\text { Indentation } \\
(\mathrm{mm})\end{array}$} & Type I & 109.3 & 108.8 & -0.4 & 101.9 & -6.8 \\
\cline { 2 - 7 } & Type II & 74.9 & 70.9 & -5.3 & 67.9 & -9.3 \\
\hline \multirow{2}{*}{$\begin{array}{c}\text { Force } \\
(\mathrm{kN})\end{array}$} & Type I & 498 & 483 & -3.0 & 649.3 & 30.4 \\
\cline { 2 - 7 } & Type II & 497.1 & 545.6 & 9.8 & 749.8 & 51.8 \\
\hline
\end{tabular}

Table 6

Comparative results at $-60^{\circ} \mathrm{C}$.

\begin{tabular}{c|c|c|c|c|c|c}
\hline & Model & Experiment & $\begin{array}{c}\text { FEA } \\
(C=3200, q=5)\end{array}$ & Error $(\%)$ & $\begin{array}{c}\text { FEA } \\
(C=40.4, q=5)\end{array}$ & Error $(\%)$ \\
\hline \multirow{2}{*}{$\begin{array}{c}\text { Indentation } \\
(\mathrm{mm})\end{array}$} & Type I & 104.1 & 116.1 & 11.5 & 106.2 & 2.0 \\
\cline { 2 - 7 } & Type II & - & - & - & - & - \\
\hline \multirow{2}{*}{$\begin{array}{c}\text { Force } \\
(\mathrm{kN})\end{array}$} & Type I & 660.3 & 656.8 & -0.5 & 790.7 & 19.7 \\
\cline { 2 - 7 } & Type II & - & - & - & - & - \\
\hline
\end{tabular}

Table 7

Total energy absorption.

\begin{tabular}{c|c|c|c|c|c|c}
\hline \multirow{2}{*}{ Temperature $\left({ }^{\circ} \mathrm{C}\right)$} & Model & Experiment $(\mathrm{kJ})$ & $\begin{array}{c}\text { FEA }(\mathrm{kJ}) \\
(C=3200, q=5)\end{array}$ & Error $(\%)$ & $\begin{array}{c}\text { FEA }(\mathrm{kJ}) \\
(C=40.4, q=5)\end{array}$ & Error $(\%)$ \\
\hline \multirow{2}{*}{ RT } & Type I & 19.08 & 17.60 & -7.7 & 21.35 & 11.9 \\
\cline { 2 - 8 } & Type II & 21.43 & 18.53 & -13.5 & 22.27 & 3.9 \\
\hline \multirow{2}{*}{-60} & Type I & 24.81 & 26.95 & 8.7 & 24.77 & -0.14 \\
\cline { 2 - 7 } & Type II & 28.74 & 28.71 & -0.1 & 41.85 & 45.62 \\
\hline
\end{tabular}




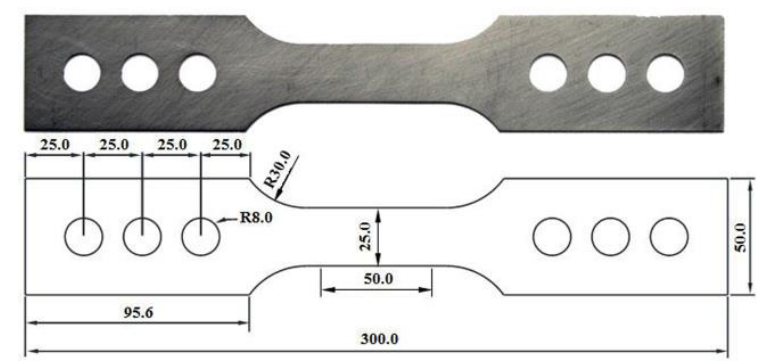

(a) Test specimen.

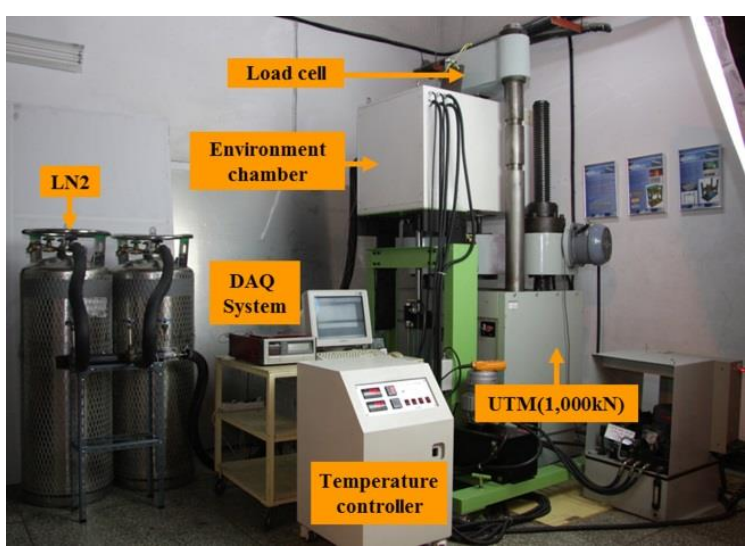

(b) Universal testing machine with an environment chamber

Fig. 1. Quasi-static test set-up. 


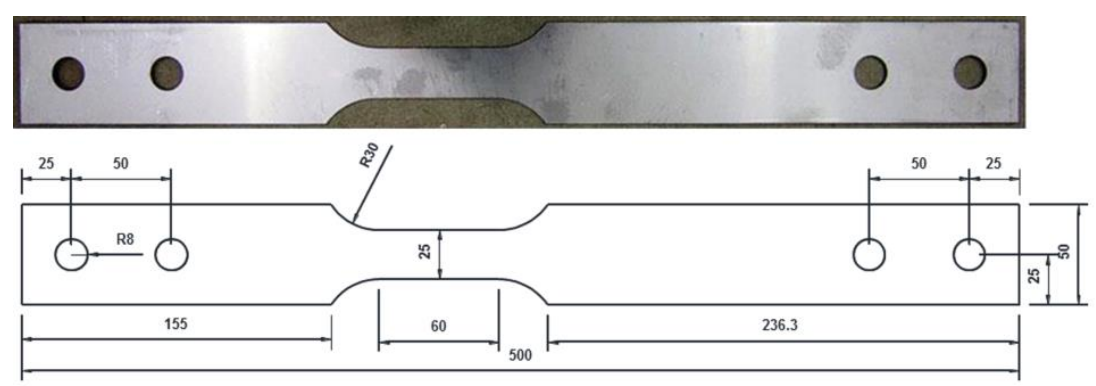

(a) Test specimen.

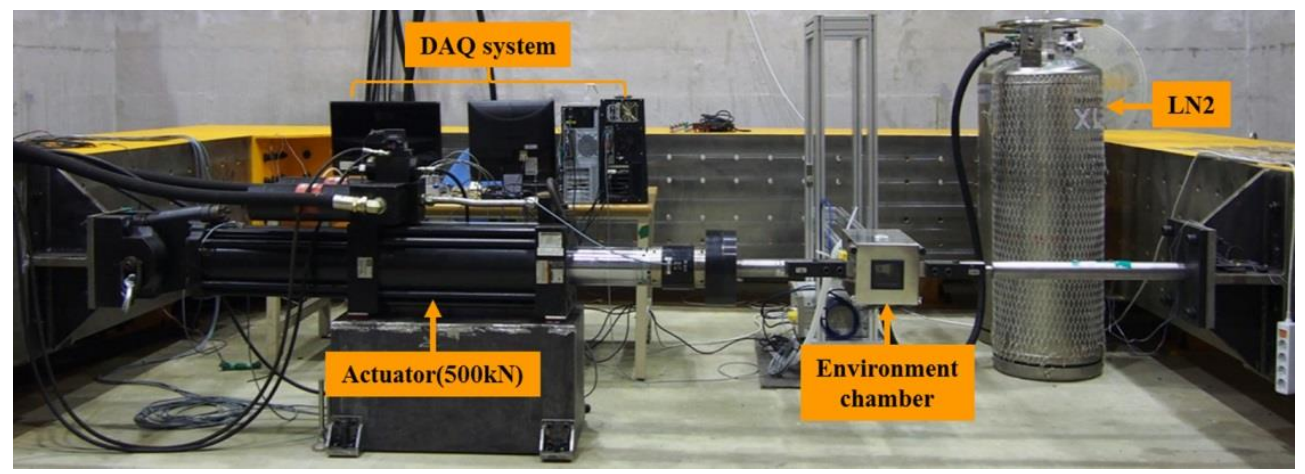

(b) MTS servo-hydraulic testing machine with an environment chamber.

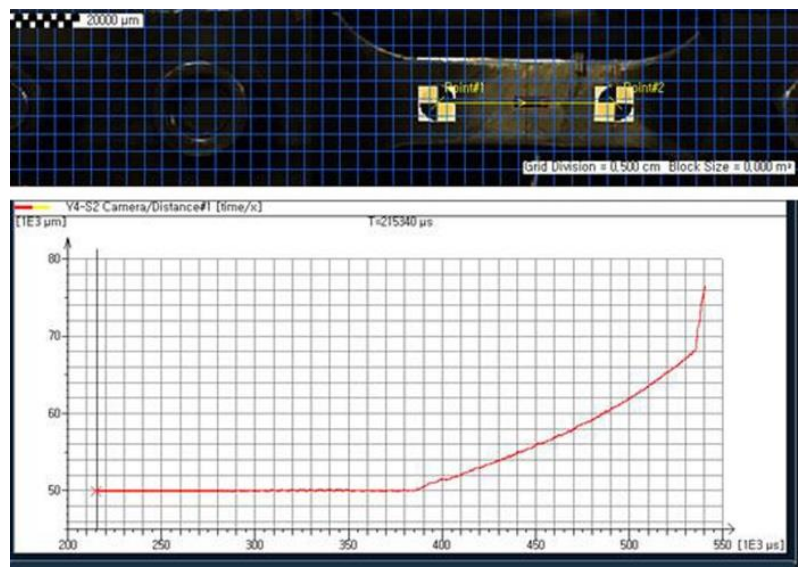

(c) Displacement measurement by DIC.

Fig. 2. Dynamic test set-up. 
For publication in International Journal of Impact Engineering

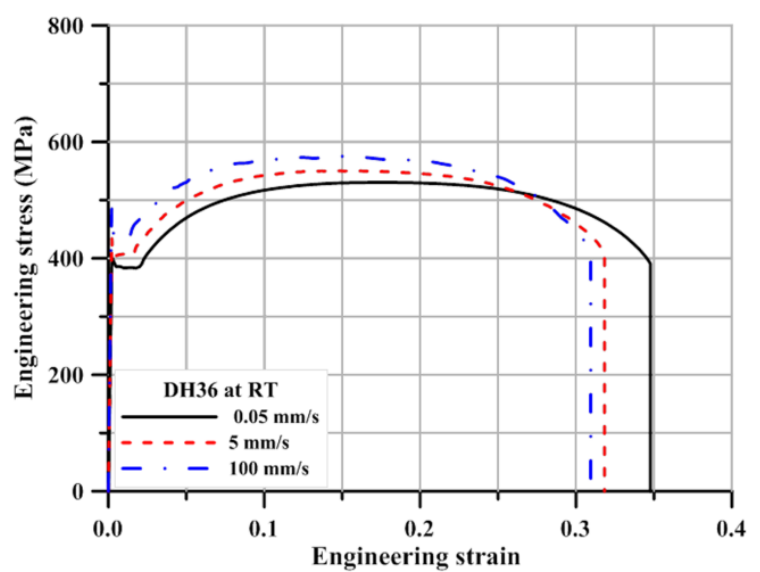

(a) RT.

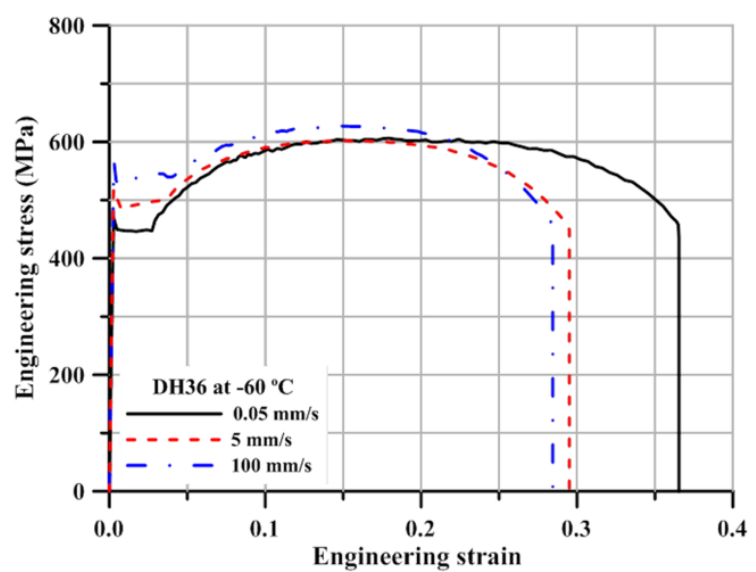

(b) $-60{ }^{\circ} \mathrm{C}$.

Fig. 3. Engineering stress-strain curves with different velocities. 


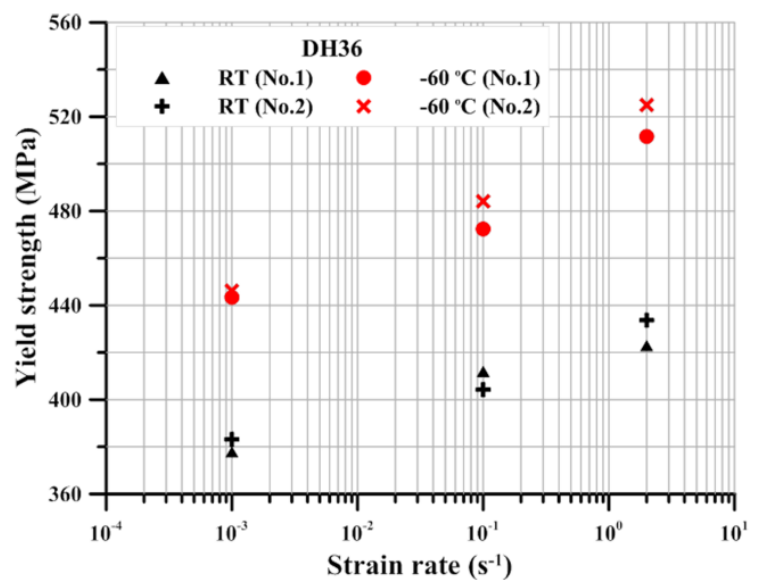

(a) Yield strength.

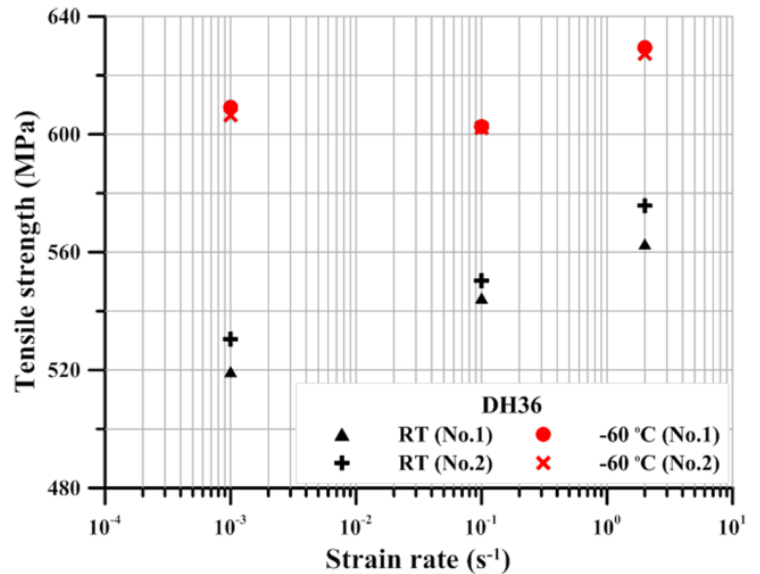

(b) Tensile strength.

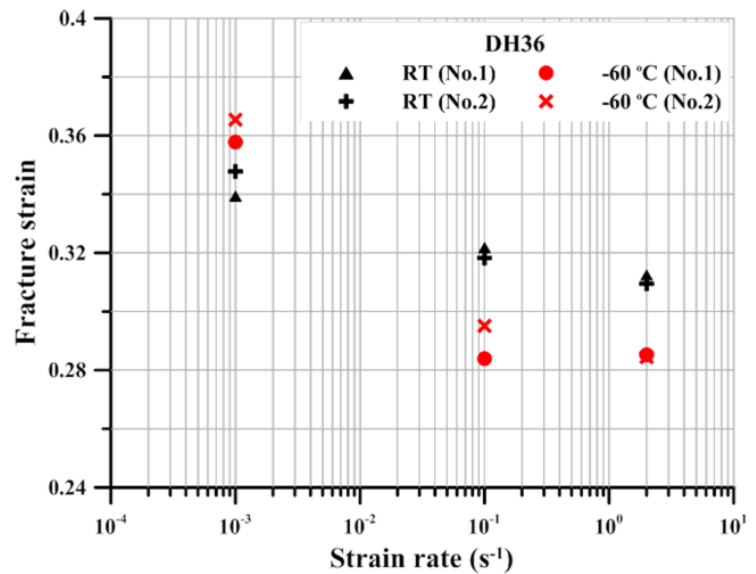

(c) Fracture strain.

Fig. 4. Mechanical properties of DH36 as a function of strain rate. 


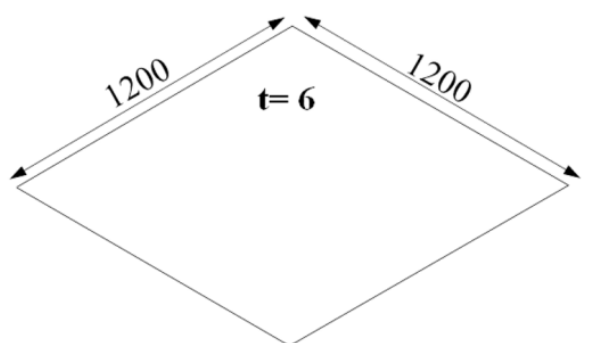

Type I

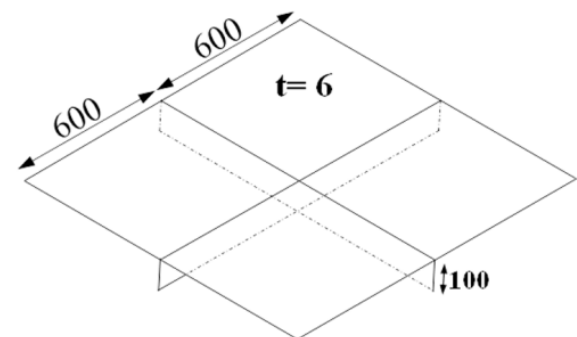

Type II

Fig. 5. Structural specimens for the dropped-object test. 


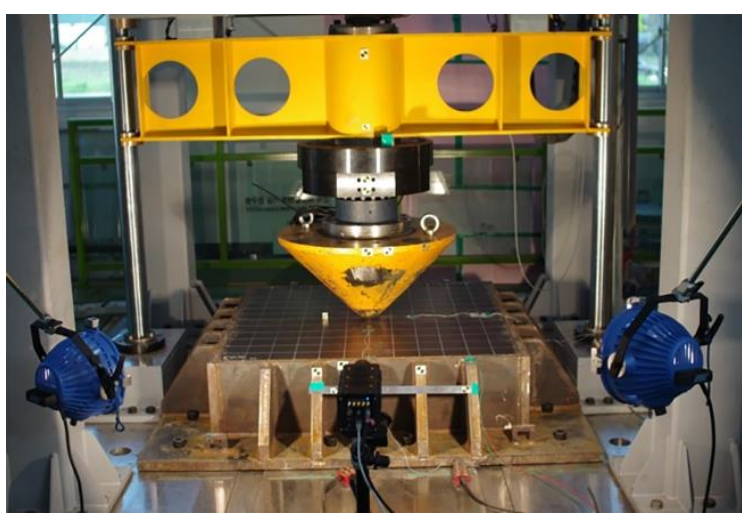

(a) Dropped-object test facility and test models with installed high-speed camera.

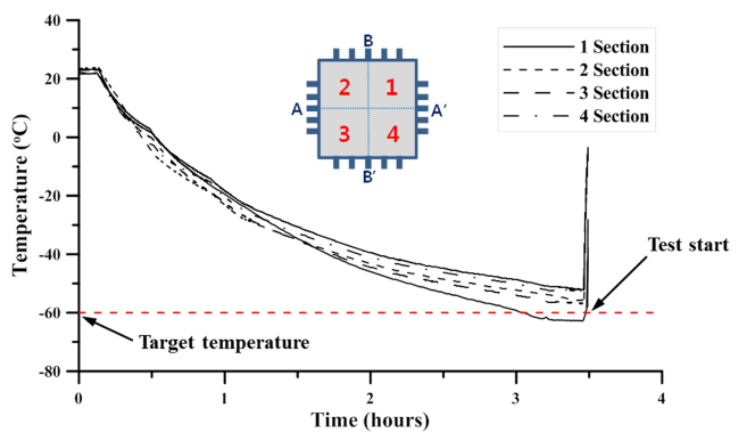

(c) Temperature history.

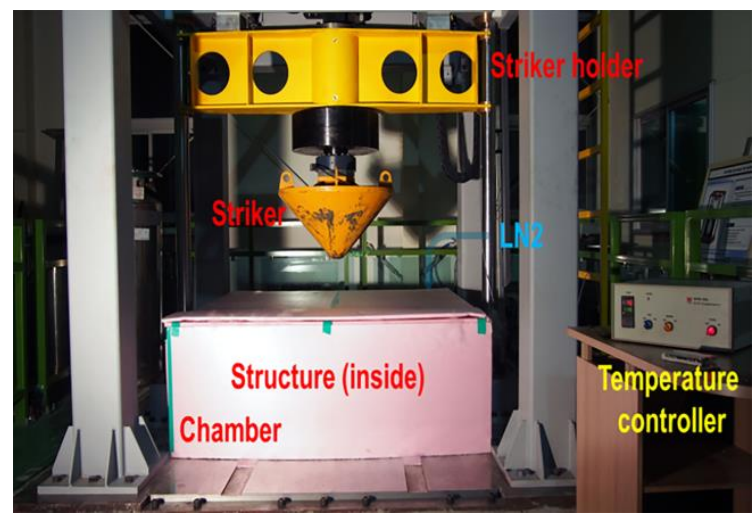

(b) Low temperature chamber.

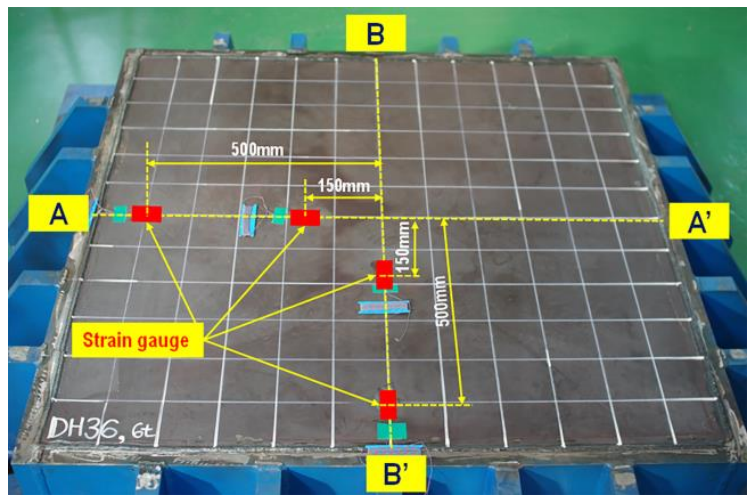

(d) Strain gauge location.

Fig. 6. Experimental set-up. 
For publication in International Journal of Impact Engineering

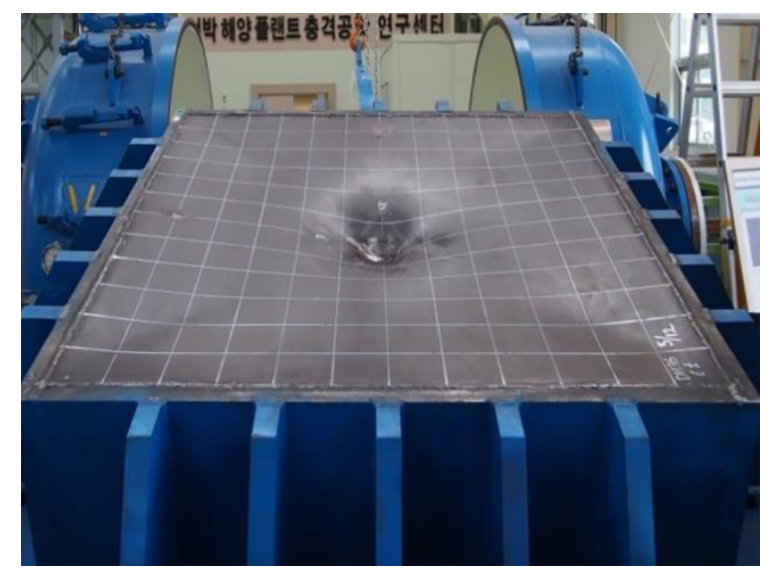

(a) Type I.

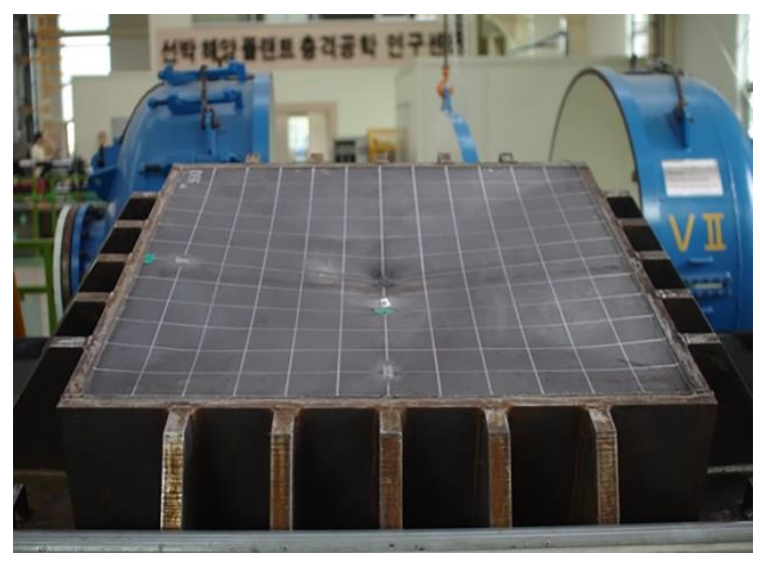

(b) Type II.

Fig. 7. Test models after test at RT. 


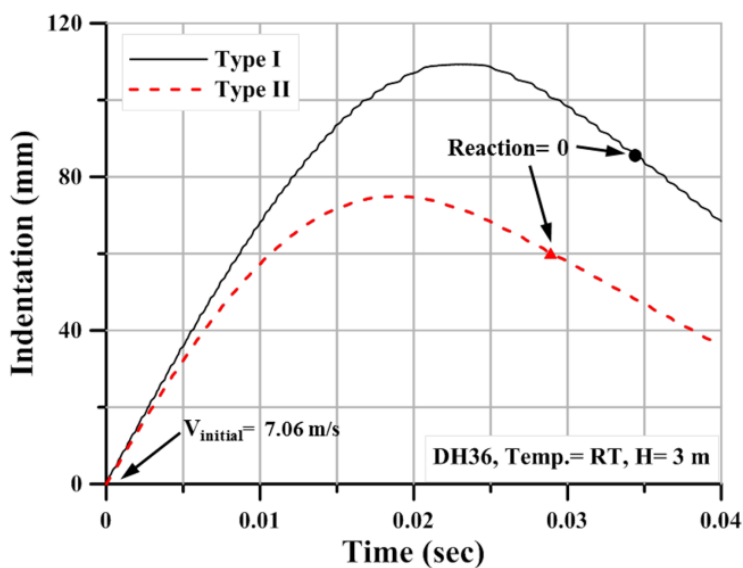

(a) Indentation-time curves.

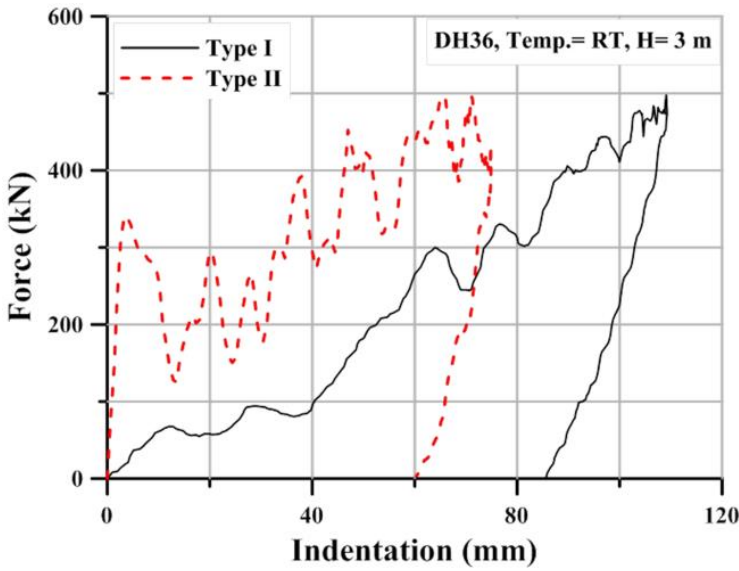

(c) Force-indentation curves.

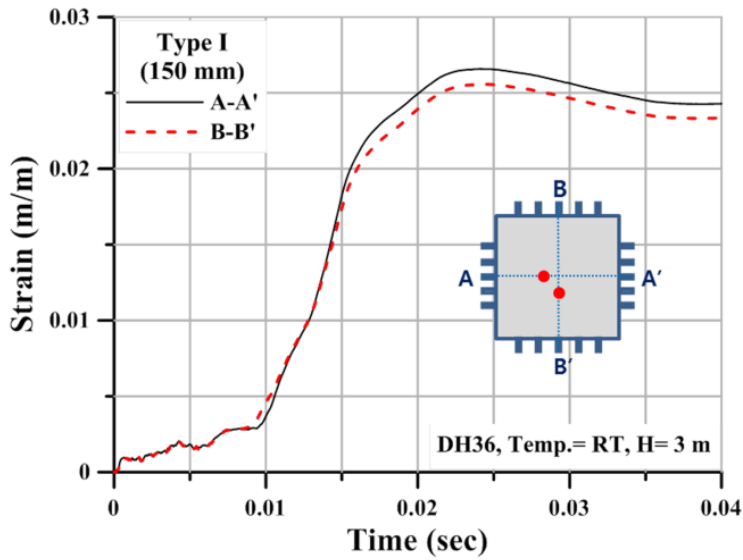

(e) Strain-time curves for type I model at $150 \mathrm{~mm}$.

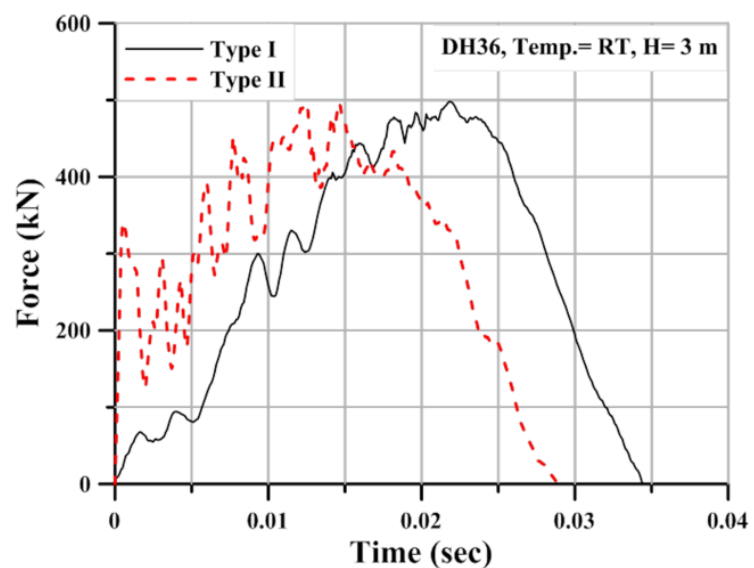

(b) Force-time curves.

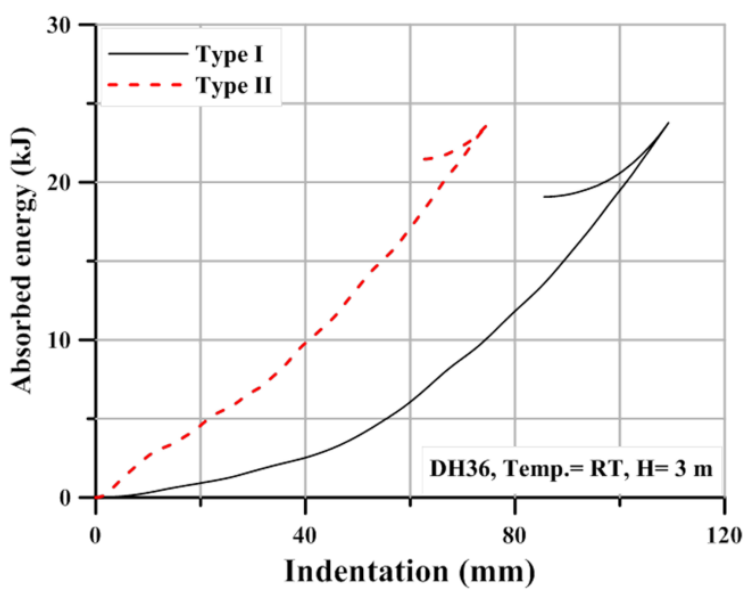

(d) Absorbed energy-indentation curves.

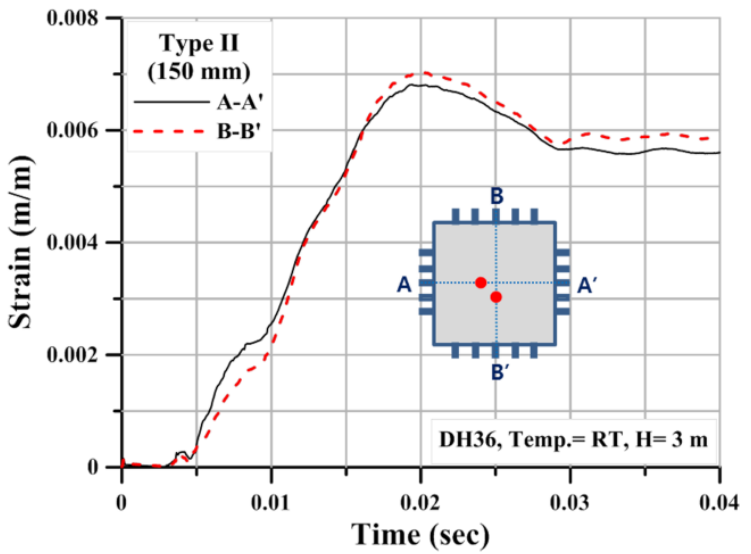

(f) Strain-time curves for type II model at $150 \mathrm{~mm}$. 
For publication in International Journal of Impact Engineering

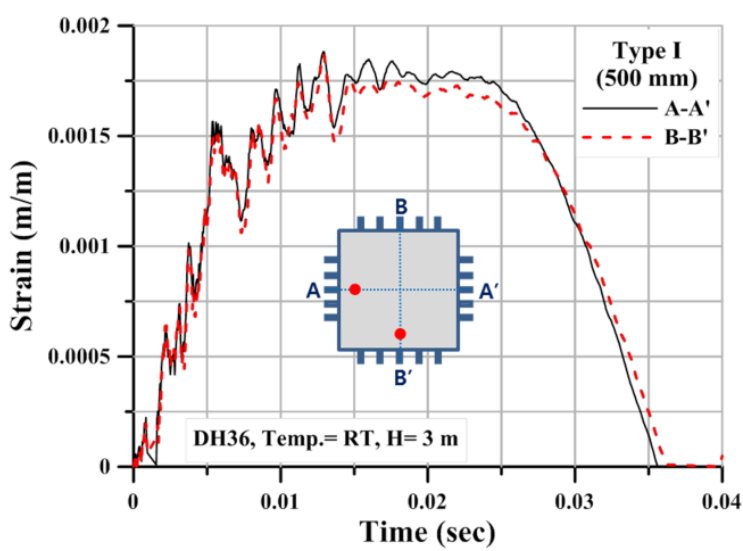

(g) Strain-time curves for type I model at $500 \mathrm{~mm}$.

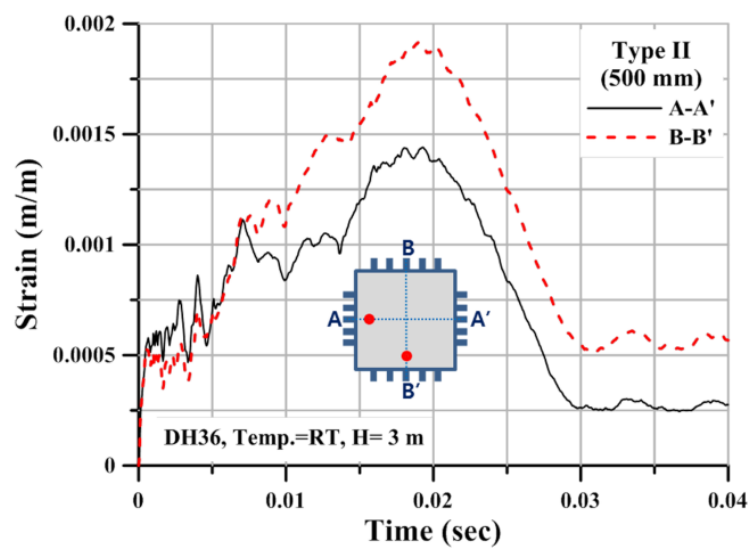

(h) Strain-time curves for type II model at $500 \mathrm{~mm}$.

Fig. 8. Test results at RT. 
For publication in International Journal of Impact Engineering

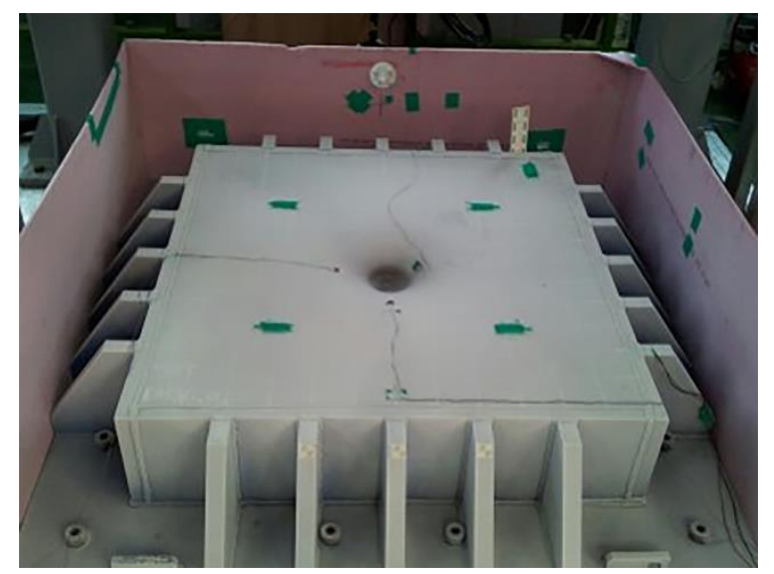

(a) Type I.

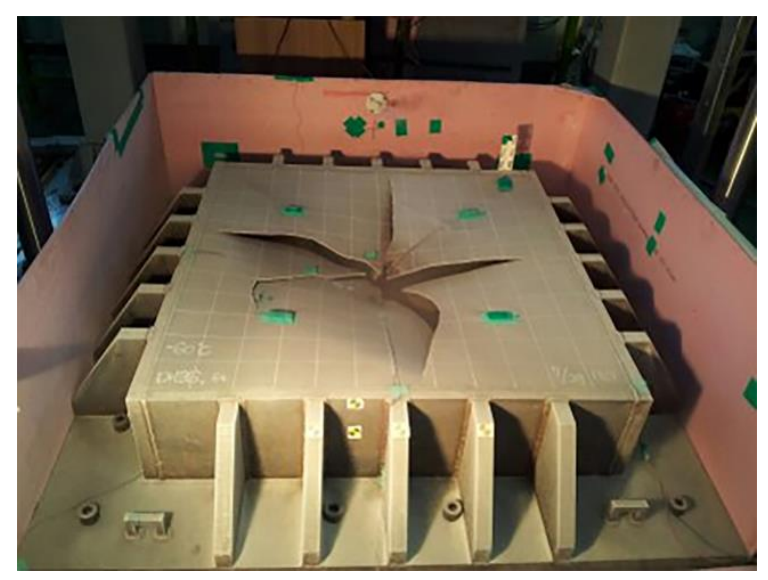

(b) Type II.

Fig. 9. Test models after test at $-60^{\circ} \mathrm{C}$. 


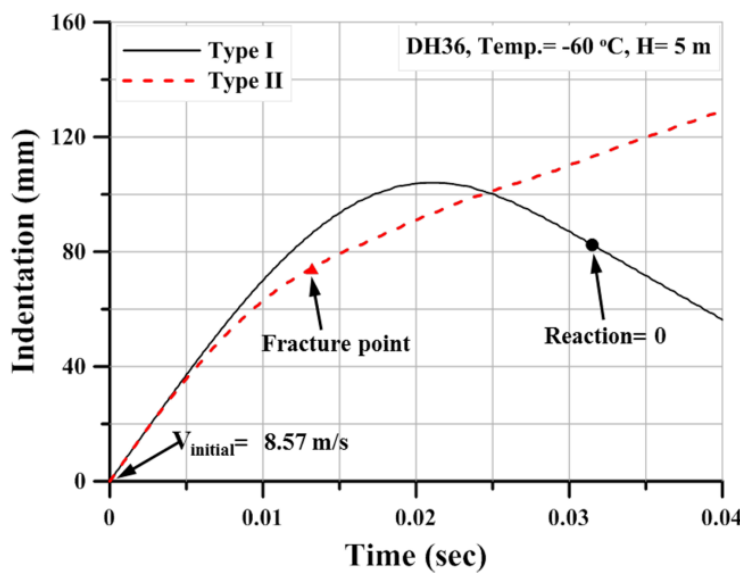

(a) Indentation-time curves.

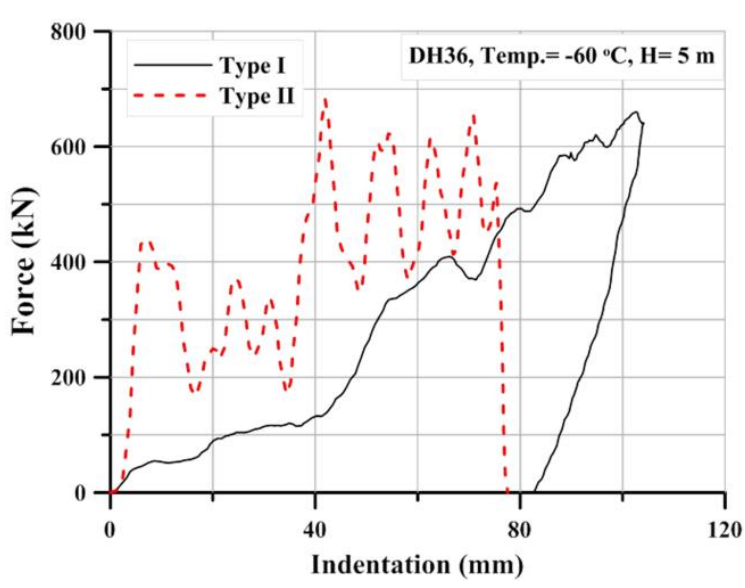

(c) Force-indentation curves.

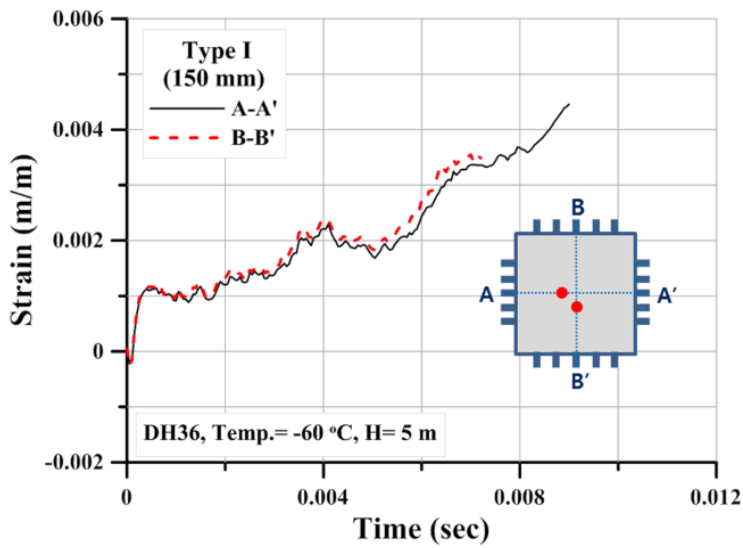

(e) Strain-time curves for type I model at $150 \mathrm{~mm}$.

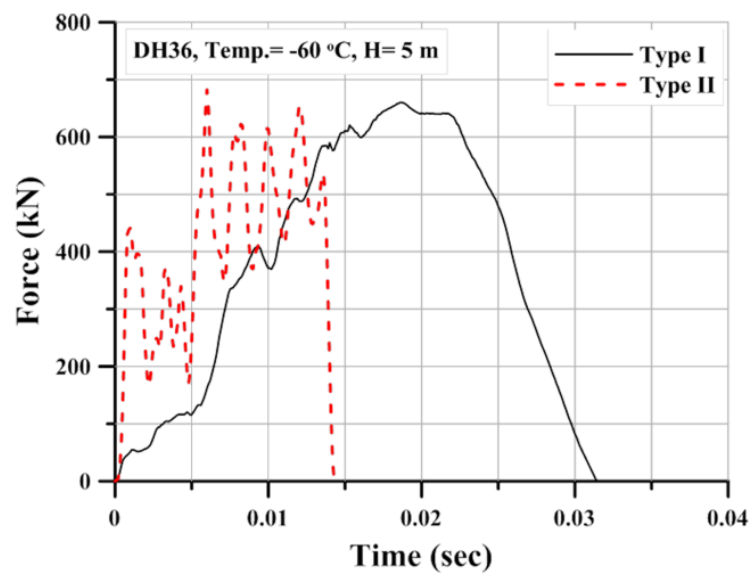

(b) Force-time curves.

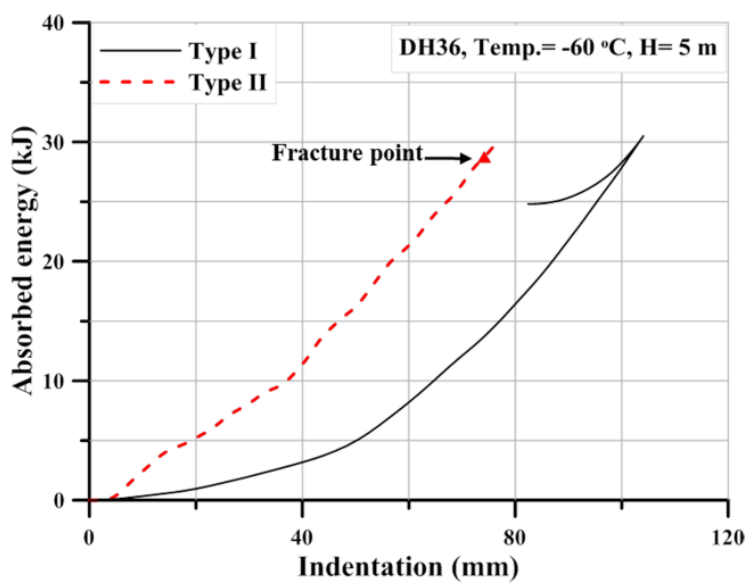

(d) Absorbed energy-indentation curves.

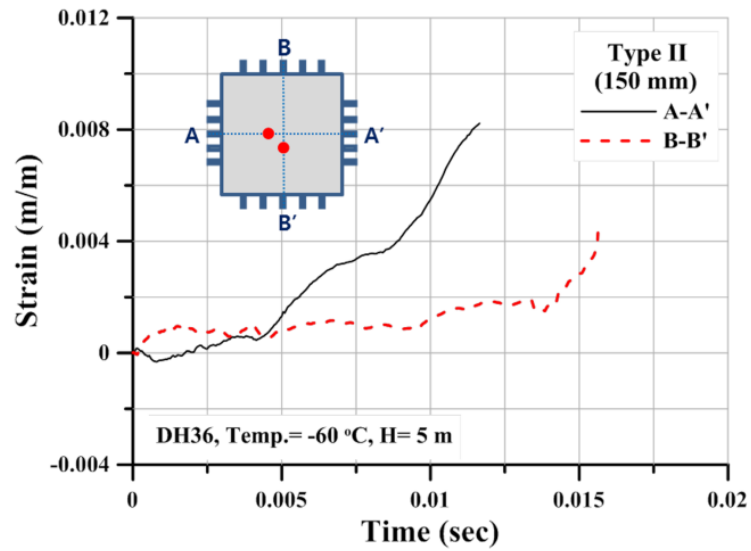

(f) Strain-time curves for type II model at $150 \mathrm{~mm}$. 
For publication in International Journal of Impact Engineering

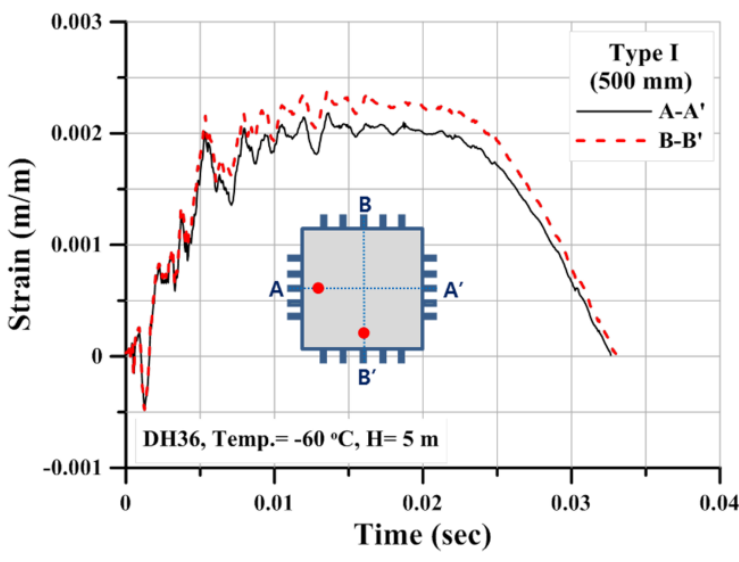

(g) Strain-time curves for type I model at $500 \mathrm{~mm}$.

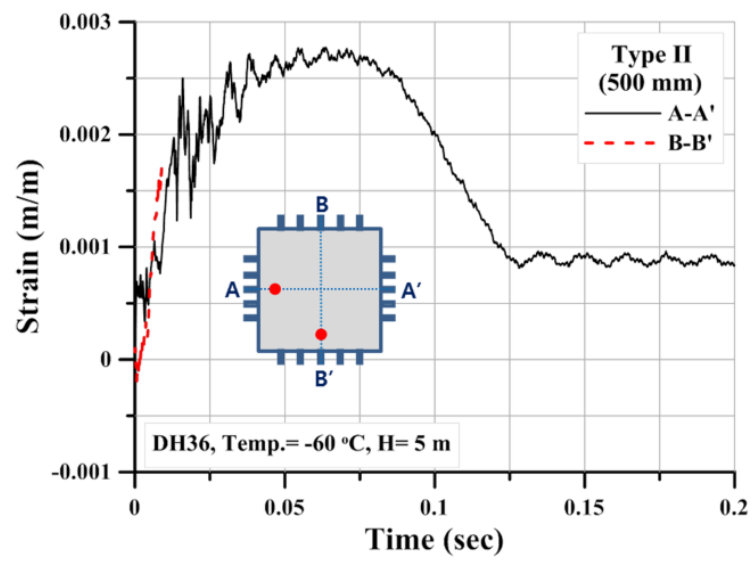

(h) Strain-time curves for type II model at $500 \mathrm{~mm}$.

Fig. 10. Test results at $-60^{\circ} \mathrm{C}$. 


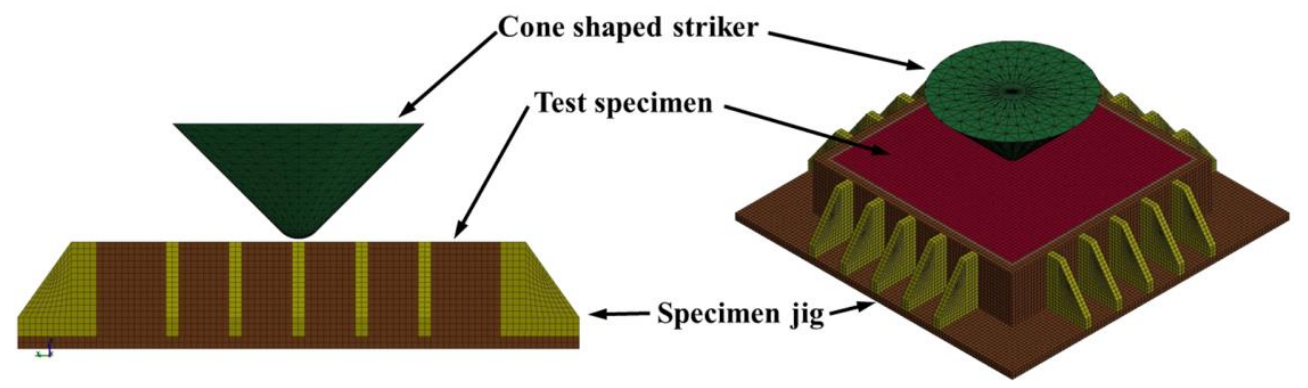

Fig. 11. Finite element model applied. 

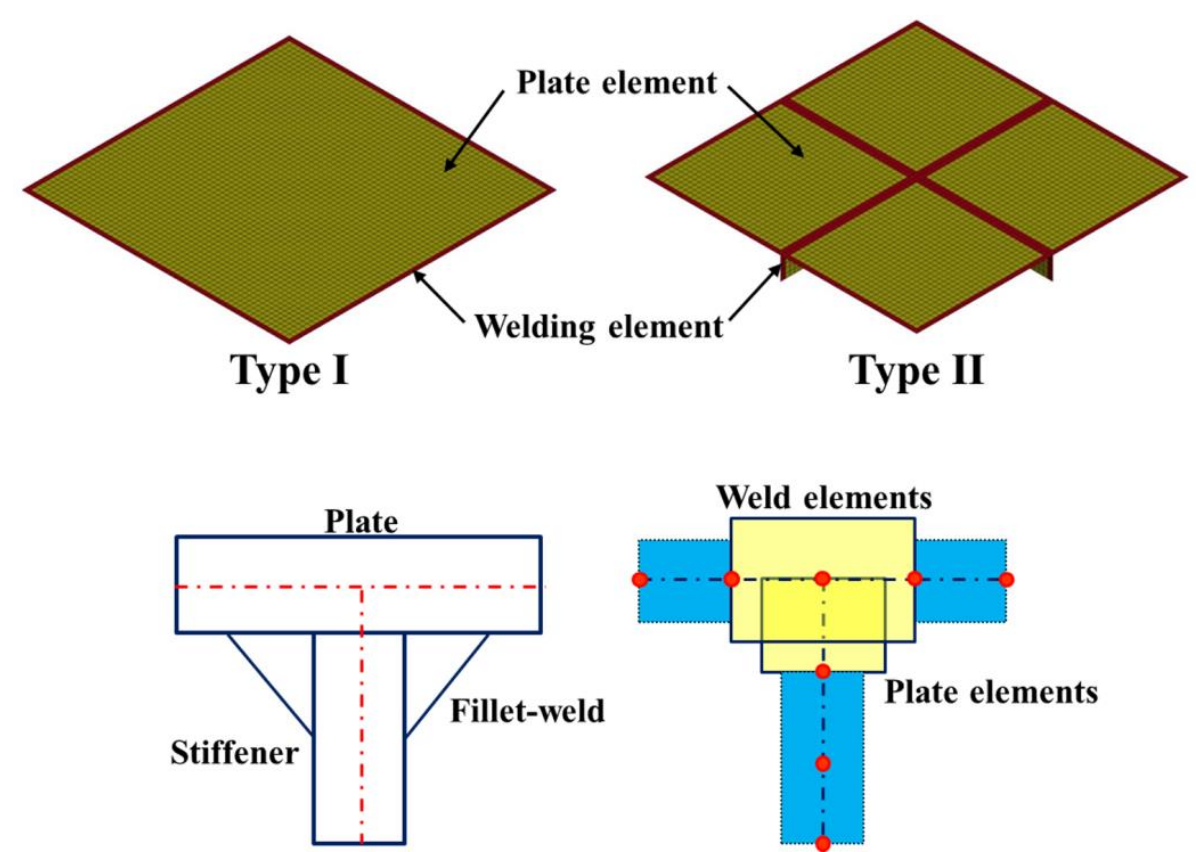

Fig. 12. Weld elements at the plate-stiffener intersections. 
For publication in International Journal of Impact Engineering

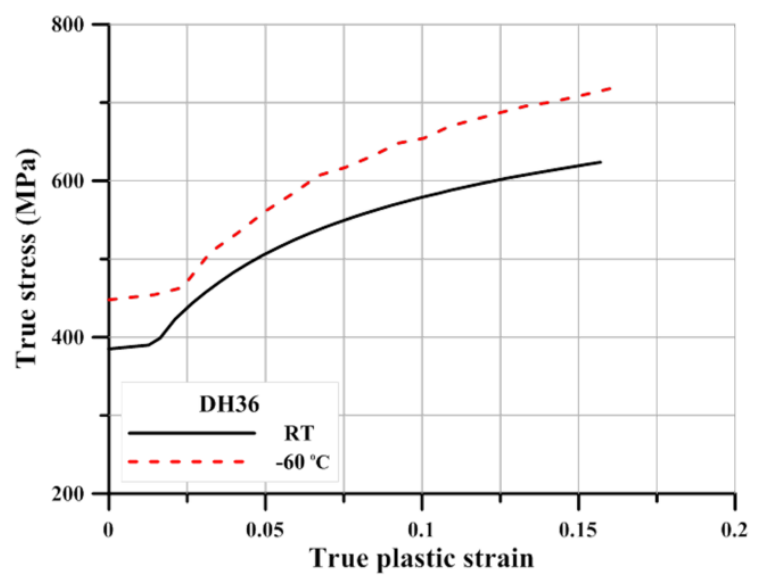

Fig. 13. True stress-true plastic strain curves. 


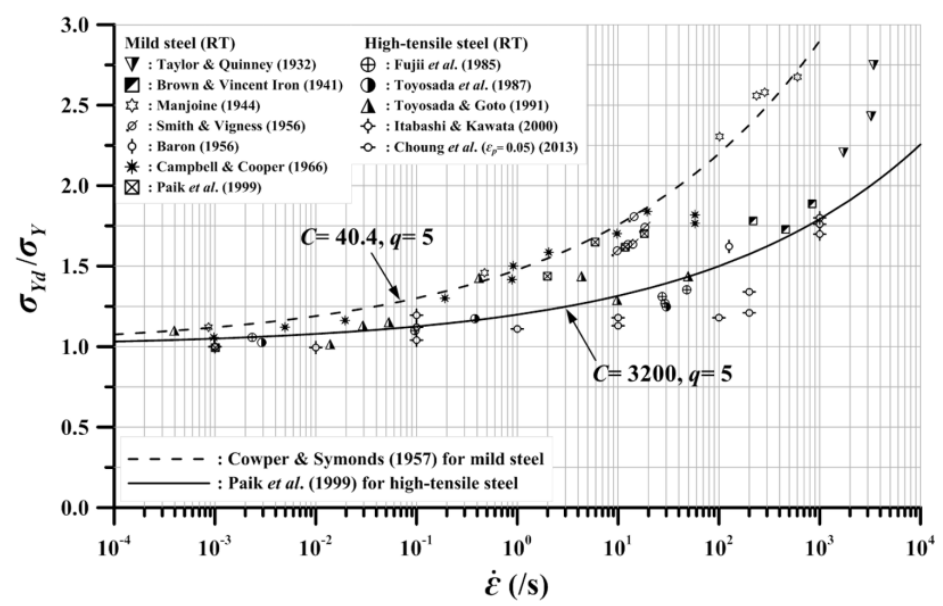

Fig. 14. Dynamic yield strength plotted versus strain rate for mild and high-tensile steel. 
For publication in International Journal of Impact Engineering

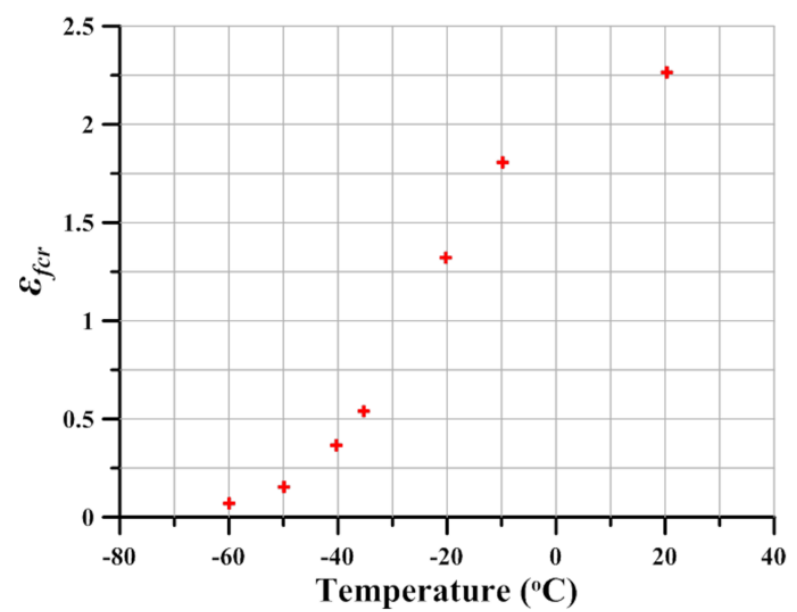

Fig. 15. Critical fracture strain for FE simulations. 


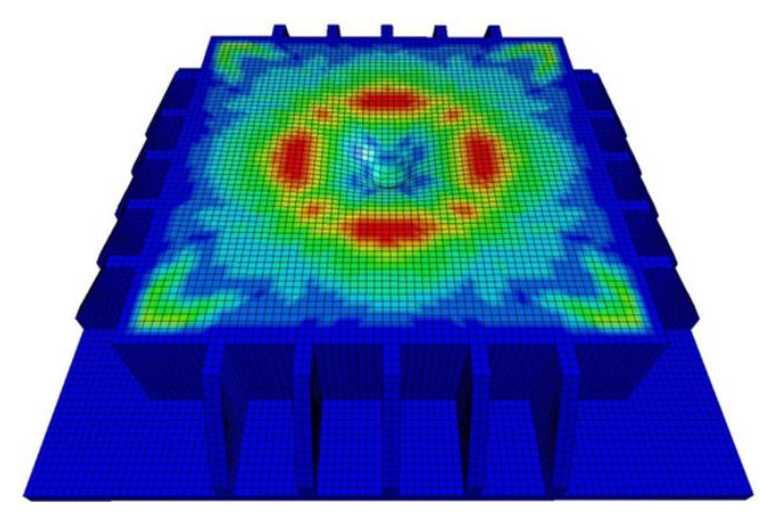

(a) $C=3200$ and $q=5$.

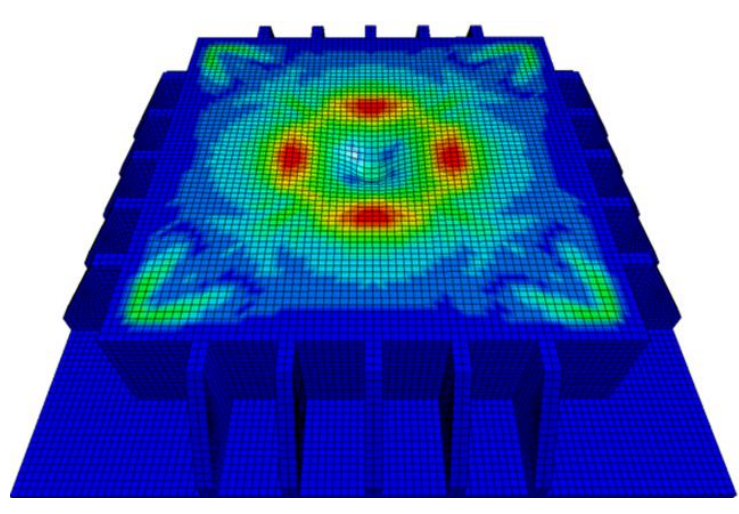

(b) $C=40.4$ and $q=5$.

Fig. 16. Stress distribution for type I model at RT. 
For publication in International Journal of Impact Engineering

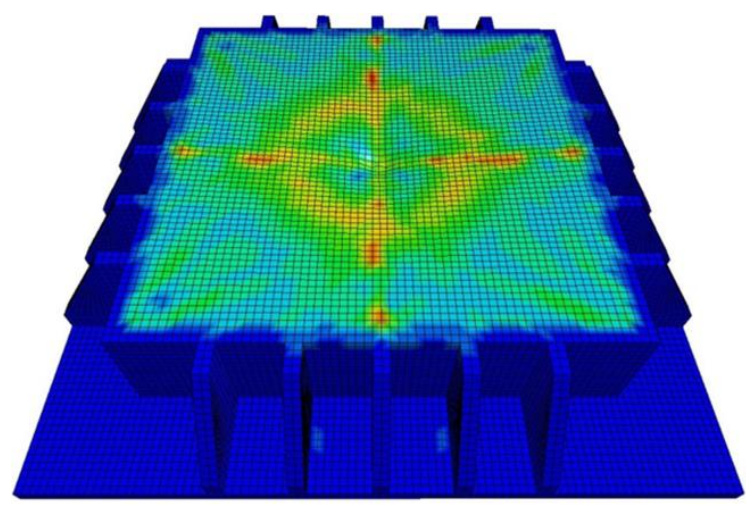

(a) $C=3200$ and $q=5$.

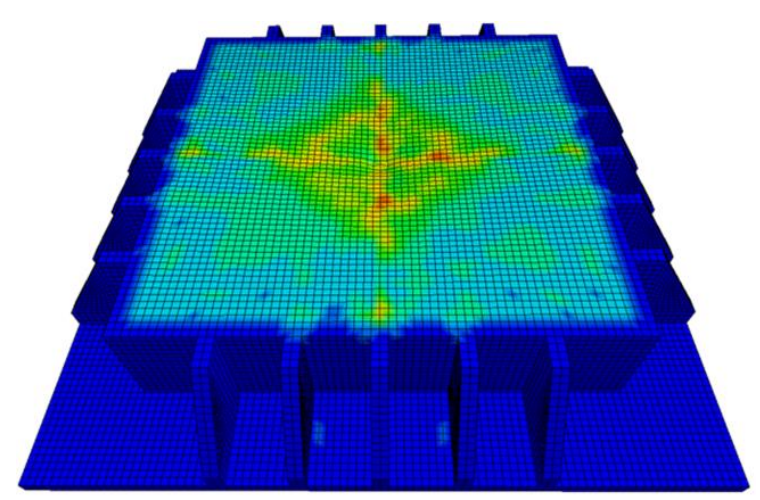

(b) $C=40.4$ and $q=5$.

Fig. 17. Stress distribution for type II model at RT. 


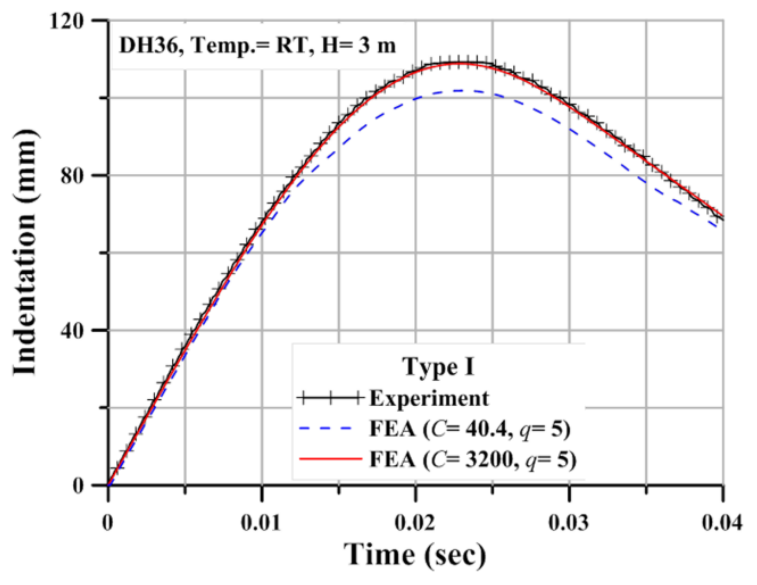

(a) Indentation-time curves for type I model.

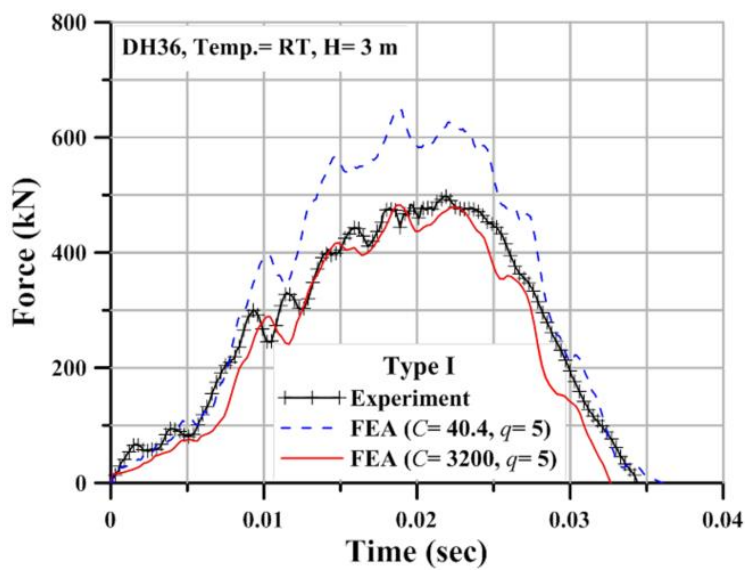

(a) Force-time curves for type I model.

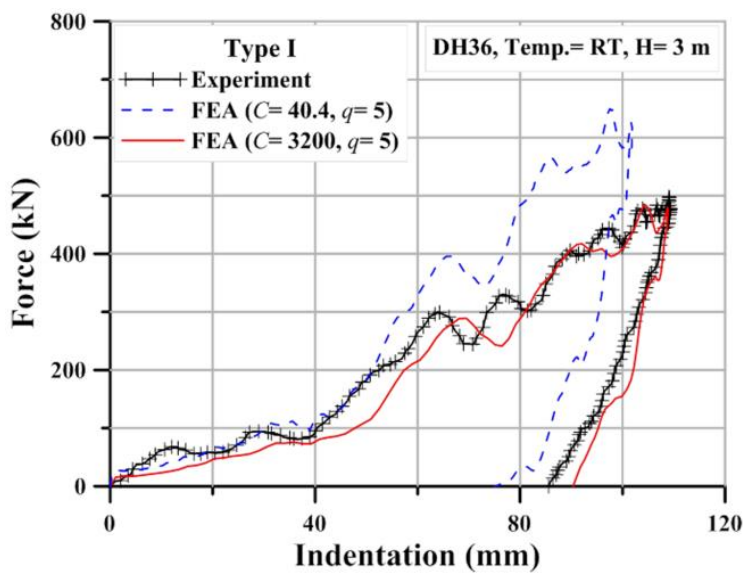

(e) Force-indentation curves for type I model.

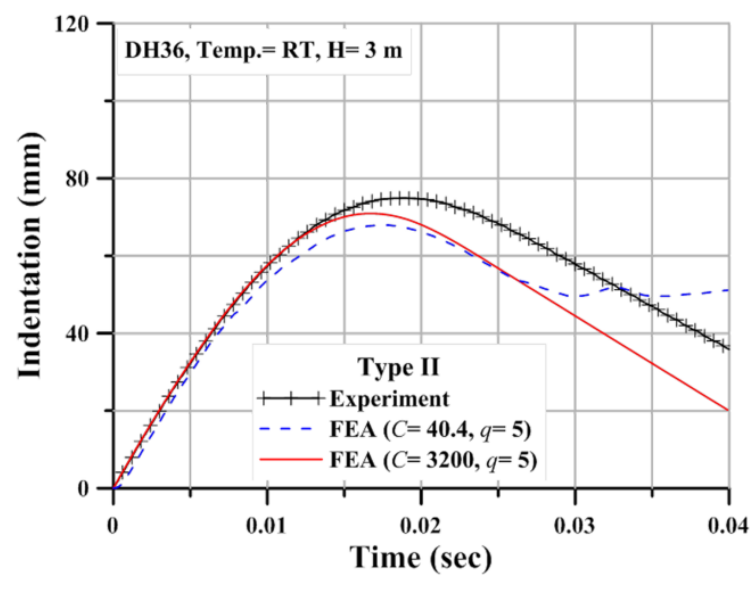

(b) Indentation-time curves for type II model.

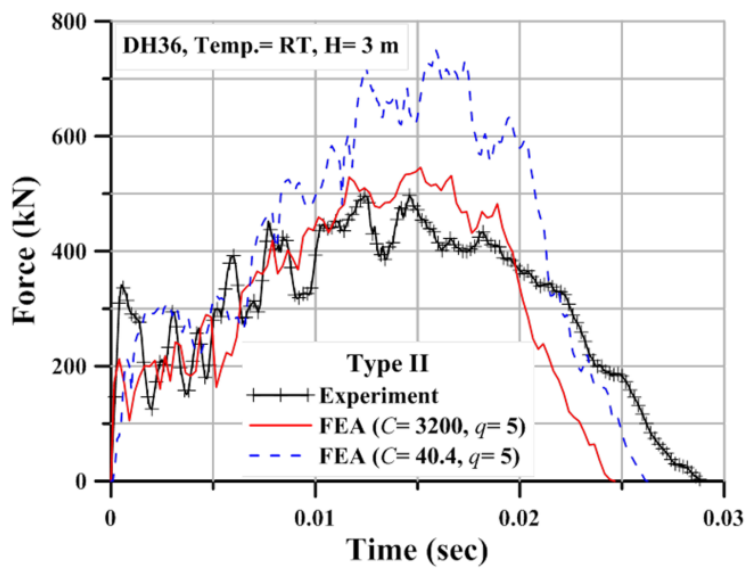

(b) Force-time curves for type II model.

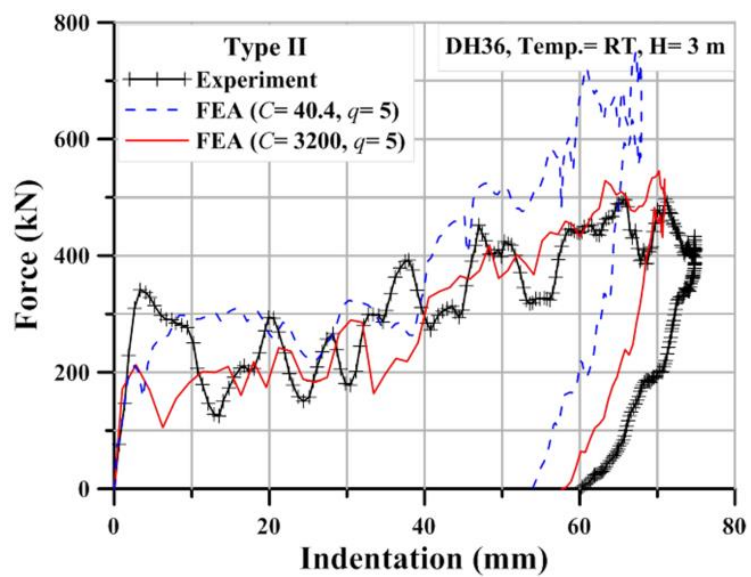

(f) Force-indentation curves for type II model. 


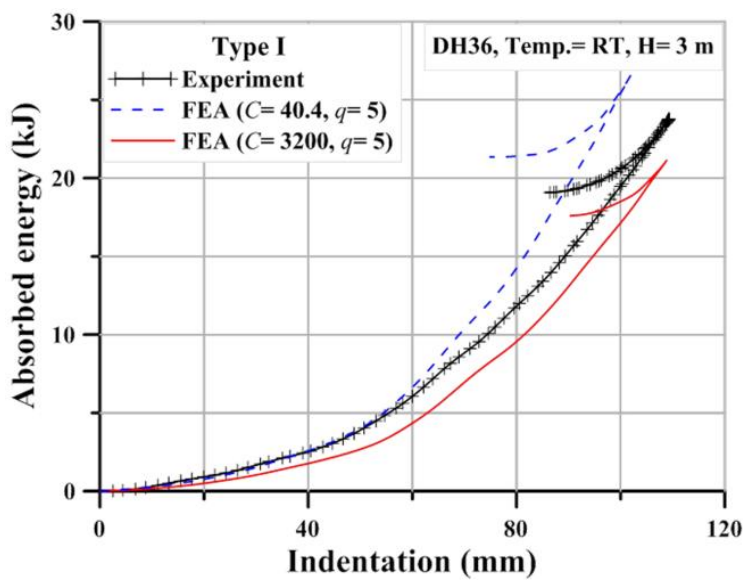

(g) Absorbed energy-indentation curves for type I model.

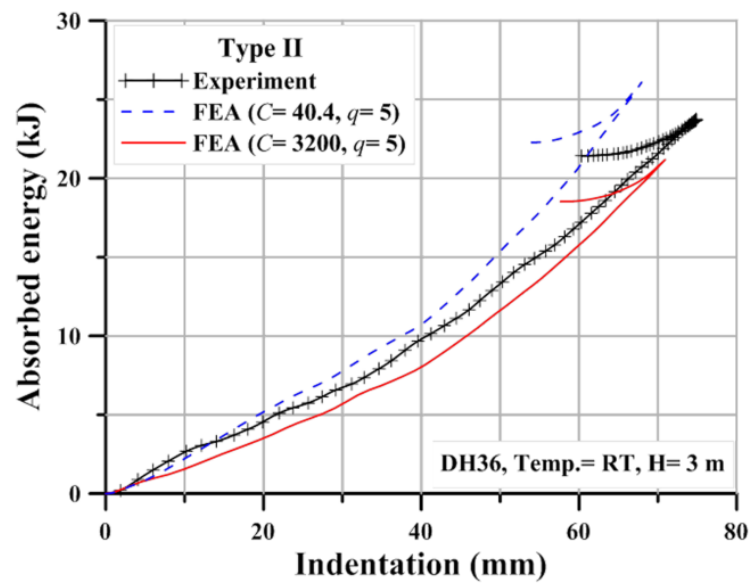

(h) Absorbed energy-indentation curves for type II model.

Fig. 18. Comparison of results at RT. 
For publication in International Journal of Impact Engineering

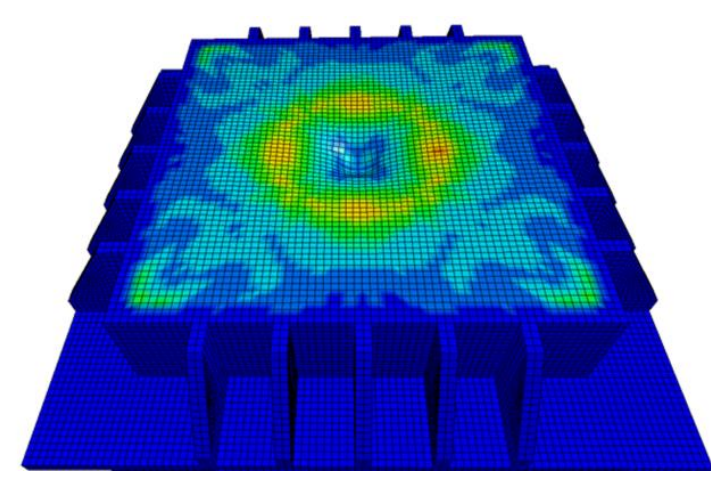

(a) $C=3200$ and $q=5$.

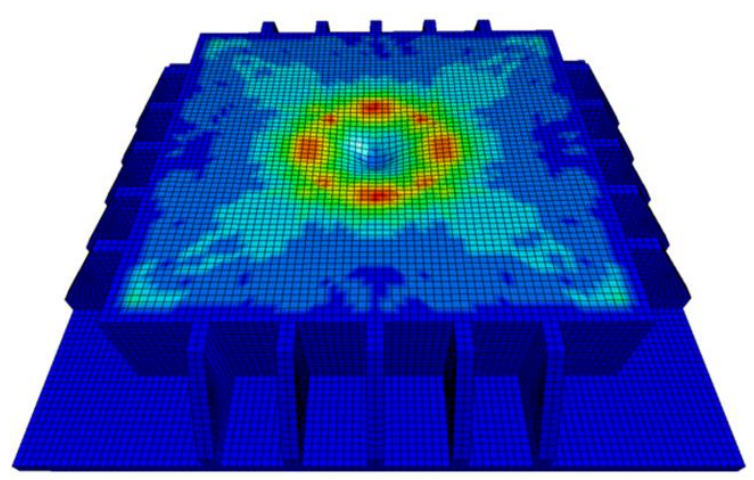

(b) $C=40.4$ and $q=5$.

Fig. 19. Stress distribution for type I model at $-60{ }^{\circ} \mathrm{C}$. 
For publication in International Journal of Impact Engineering

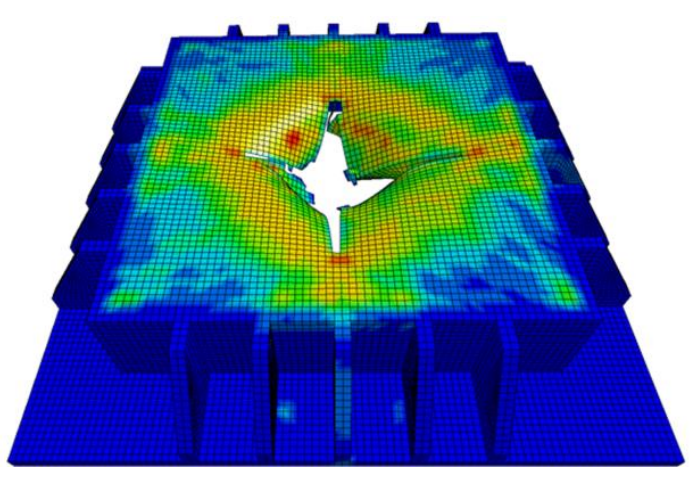

(a) $C=3200$ and $q=5$.

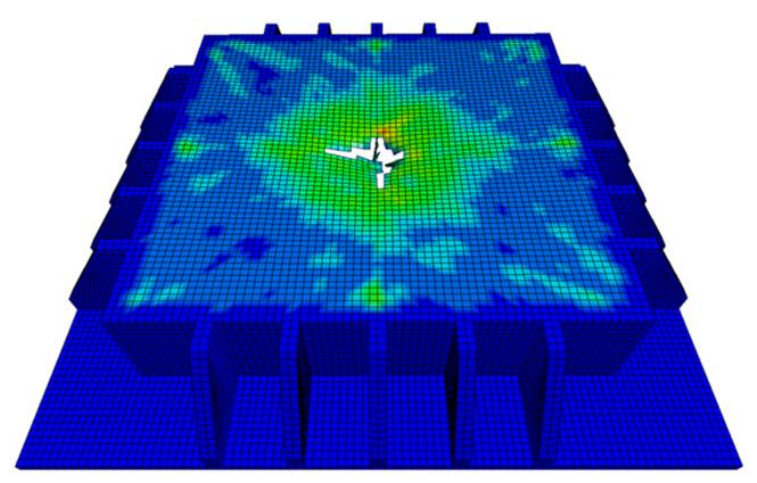

(b) $C=40.4$ and $q=5$.

Fig. 20. Stress distribution for type II model at $-60{ }^{\circ} \mathrm{C}$. 


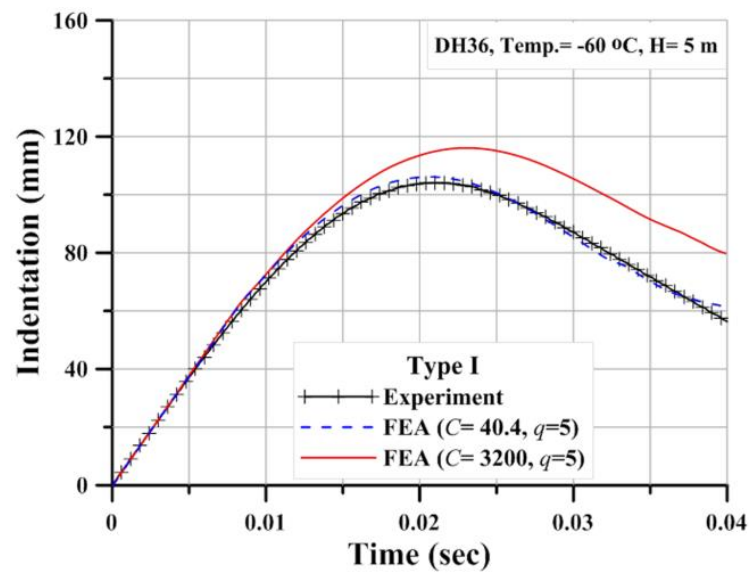

(a) Indentation-time curves for type I model.

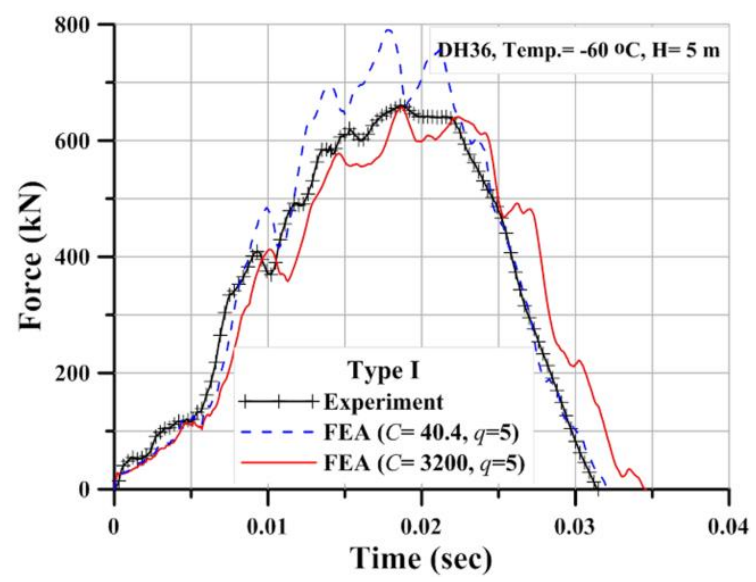

(c) Force-time curves for type I model.

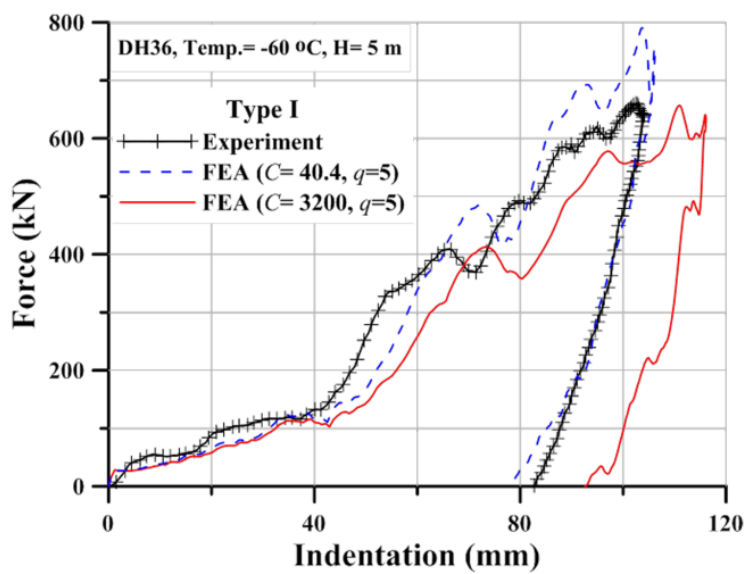

(e) Force-indentation curves for type I model.

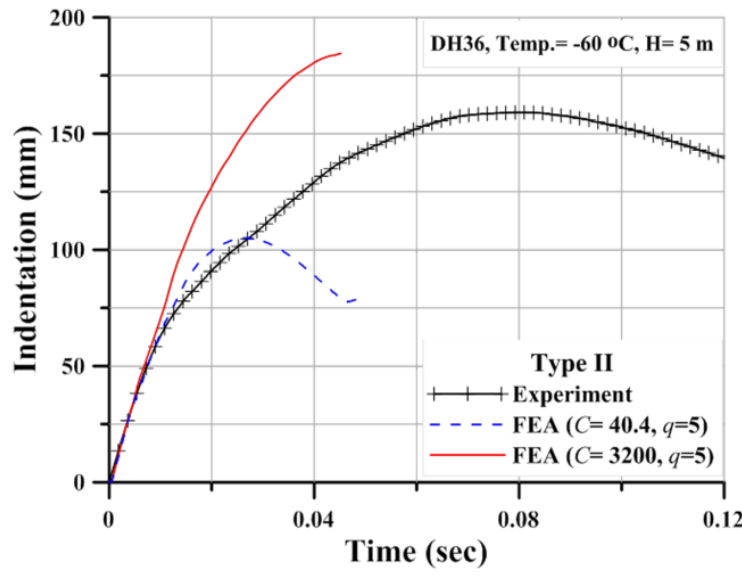

(b) Indentation-time curves for type II model.

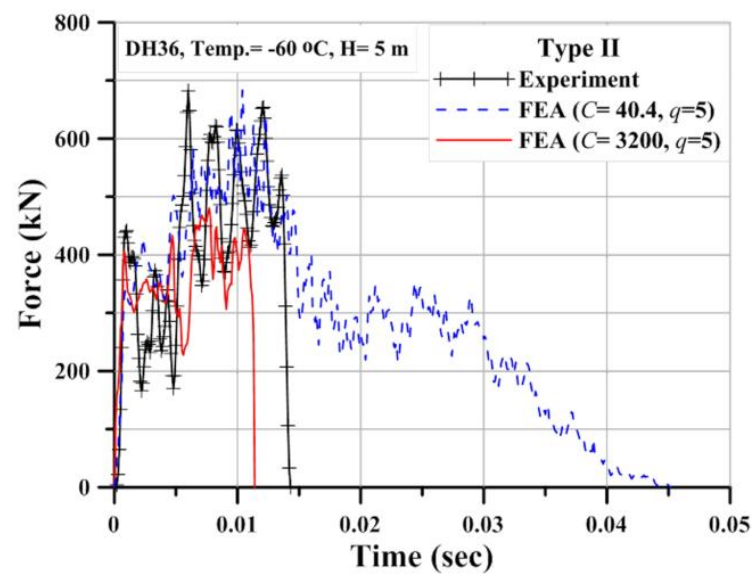

(d) Force-time curves for type II model.

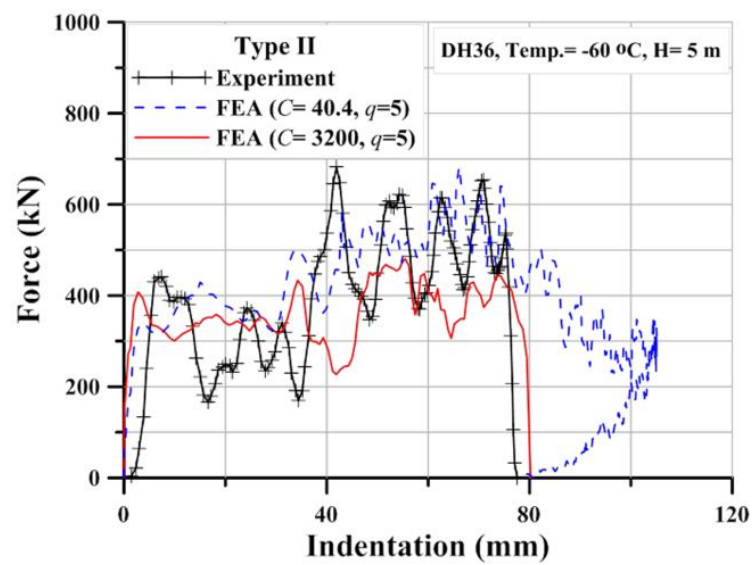

(f) Force-indentation curves for type II model. 


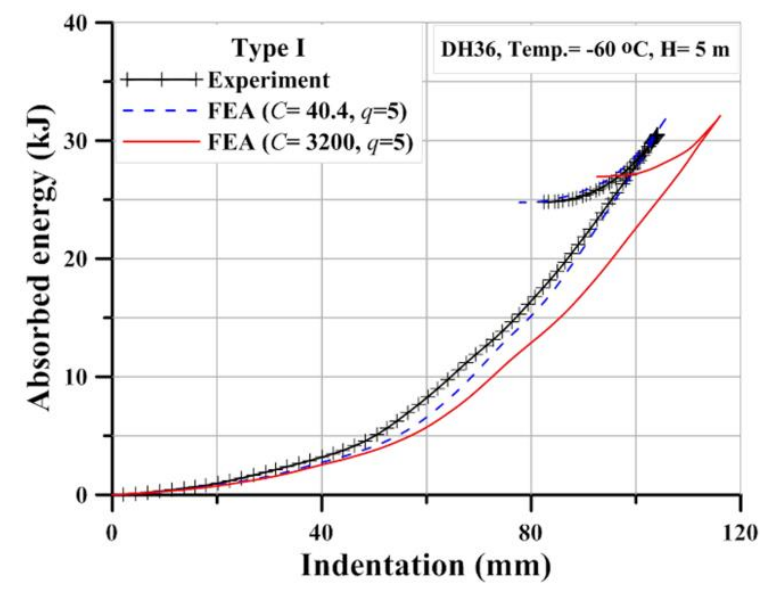

(g) Absorbed energy-indentation curves for type I model.

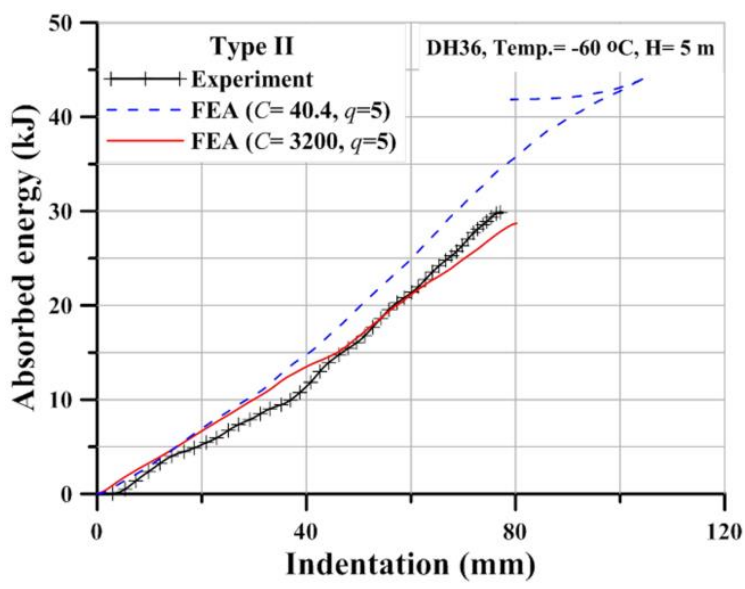

(h) Absorbed energy-indentation curves for type II model.

Fig. 21. Comparison of results at $-60^{\circ} \mathrm{C}$. 
For publication in International Journal of Impact Engineering
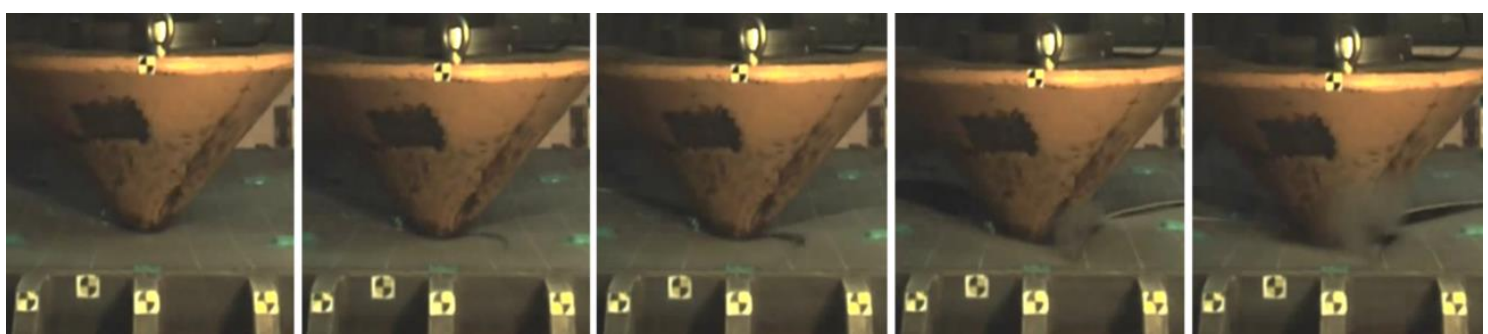

Fig. 22. Brittle fracture for type II model at $-60{ }^{\circ} \mathrm{C}$. 
For publication in International Journal of Impact Engineering

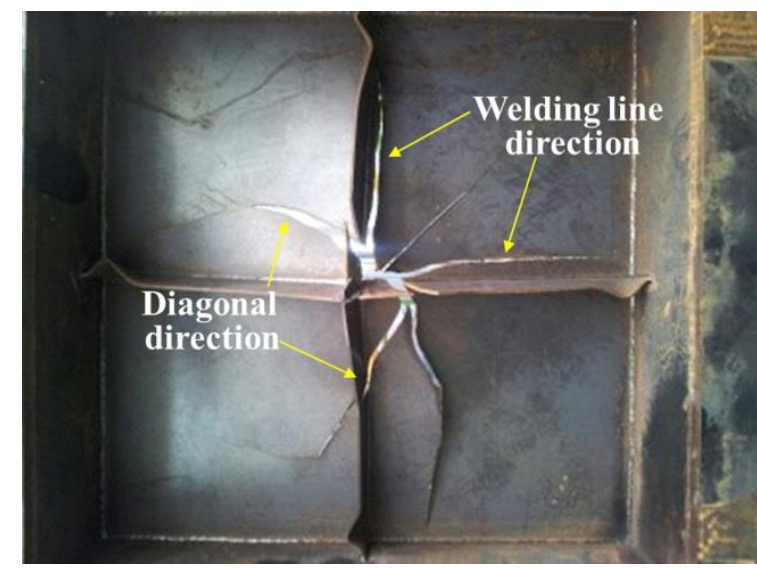

(a) Crack propagation.

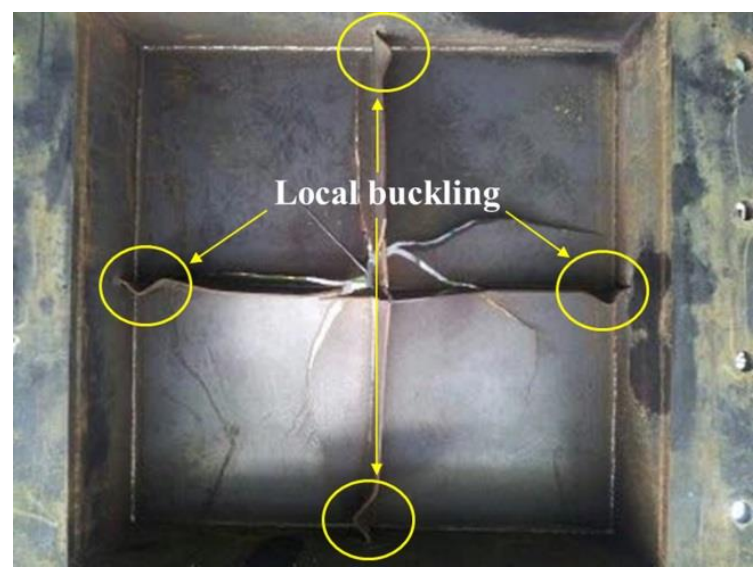

(b) Local buckling.

Fig. 23. Bottom of type II model at $-60^{\circ} \mathrm{C}$. 